\title{
Los Claroscuros del EBEP en los procedimientos de concurrencia competitiva: reflexiones empíricas y propuestas innovadoras
}

\section{The Claroscuros of the EBEP in the concurrence proceedings competitive: empirical reflections and innovative proposals}

\author{
Jorge Fondevila Antolín \\ Gobierno de Cantabria (España) \\ fondevila_j@telefonica.net
}

\section{NOTA BIOGRÁFICA}

Doctor en Derecho; Funcionario de habilitación carácter nacional: Escala de secretaria; Funcionario del Gobierno de Cantabria: Cuerpo de Letrados y Cuerpo Técnico Superior. Jefe de Asesoría Jurídica. Las líneas de investigación desarrolladas son esencialmente empleo público, e-administración y contratación electrónica, en estas áreas ha publicado siete monografías y participado en diecisiete publicaciones colectivas, además de múltiples artículos en revistas jurídicas.

\section{RESUMEN}

Este trabajo se ha concebido como una breve reflexión de la actual situación del empleo público, con relación a los procedimientos de concurrencia competitiva, en concreto, se examina el vigente marco legal básico (TREBEP), sus aportaciones, deficiencias y, en especial, se formulan algunas propuestas de reforma del mismo, con relación a los procedimientos selectivos para el acceso al empleo público, así, como también sobre el desarrollo de los procedimientos de provisión de puestos de trabajo, elemento este último clave en el desarrollo de la carrera administrativa de los funcionarios.

\section{PALABRAS CLAVE}

Función Pública; empleados públicos; selección; órganos de selección. Administración pública; innovación en la selección; provisión de puesto de trabajo; carrera administrativa.

\begin{abstract}
This work has been conceived as a brief reflection of the current situation of public employment, in relation to competitive competition procedures, specifically, it examines the current basic legal framework (TREBEP), its contributions, deficiencies and, especially, formulate some proposals for its reform, in relation to the selective procedures for access to public employment, as well as the development of the procedures for the provision of jobs, the latter key element in the development of the administrative career of the functionaries.
\end{abstract}

\section{KEYWORDS}

Public Function; public employees; selection; selection bodies. Public administration; innovation in the selection; provision of job; administrative career.

\section{SUMARIO}

1. ALGUNAS CONSIDERACIONES SOBRE EL MALTRECHO ESTADO DEL EMPLEO PÚBLICO. 2. LA SELECCIÓN EN EL EMPLEO PÚBLICO. 2.1. QUÉ MEJORAS INCORPORÓ EL EBEP AL ÁMBITO DE 
LOS PROCEDIMIENTOS DE SELECCIÓN. 2.2. AUSENCIAS E INCOHERENCIAS EN EL TREBEP. 2.2.1. La composición de los órganos de selección (artículo 60 TREBEP): una regulación inacabada. 2.2.2. El Acceso del personal laboral: un sistema demasiado flexible y con un claro riesgo de interferencias. 2.2.3. Una puerta trasera de acceso inconstitucional: Disposición Transitoria 4. ${ }^{a}$ TREBEP. 2.3. ALGUNAS PROPUESTAS PARA UNA SELECCIÓN MÁS PROFESIONAL Y OBJETIVA. 2.3.1. EI imprescindible desarrollo normativo en el TREBEP de la implementación del Principio de Transparencia. 2.3.2. Reducción de la discrecionalidad técnica: el control sobre el contenido de la motivación de los órganos de selección. 2.3.3. Propuesta de una necesaria especialización de los órganos de selección según el tipo de ejercicios o pruebas a valorar. 2.3.4. Propuesta de revisión de los tipos de pruebas utilizados en los procedimientos de selección. 2.3.5. La necesidad de desarrollo de los órganos especializados y permanentes de selección: Una cuestión especialmente pendiente en las administraciones locales. 2.3.6. Una exigencia del Principio de igualdad y el Estado social: Las ayudas económicas para la preparación de los procesos selectivos. 2.4. UN BREVE EXAMEN DE LA JURISPRUDENCIA DEL TRIBUNAL SUPREMO TRAS LA APROBACIÓN DEL EBEP: REDUCCIÓN DE LA DISCRECIONALIDAD TÉCNICA Y LA INCORPORACIÓN DEL PRINCIPIO DE TRANSPARENCIA. 2.4.1. Reducción de la discrecionalidad técnica: el control sobre el contenido de la motivación de los órganos de selección. 2.4.2. La acreditación en vía de recurso administrativo y en el procedimiento judicial del desacierto de la actuación del órgano de selección mediante la práctica de una prueba pericial. 2.4.3. El Principio de Transparencia en los procesos selectivos: una exigencia ineludible. 3. UNA CARRERA ADMINISTRATIVA PROFESIONAL O POLITIZADA: LOS PROCEDIMIENTOS DE PROVISIÓN DE PUESTOS DE TRABAJO. 3.1. EXAMEN DE LOS «PROBLEMÁTICOS»PROCEDIMIENTOS DE PROVISIÓN DE PUESTOS DE TRABAJO. 3.1.1. Provisión de Puestos de Trabajo por Libre Designación. 3.1.2. Un poco de aire fresco: La doctrina del Tribunal Supremo sobre los controles en las convocatorias, motivación y cese en los procedimientos de libre designación. 3.1.3. Propuestas para una reconducción de la Libre designación. 3.1.4. El Concurso Específico: en muchas ocasiones una libre designación encubierta. 3.1.5. Una consideración final: la necesidad de un marco normativo específico para las entidades locales. REFERENCIAS BIBLIOGRÁFICAS.

\section{ALGUNAS CONSIDERACIONES SOBRE EL MALTRECHO ESTADO DEL EMPLEO PÚBLICO ${ }^{1}$}

Para poder ofrecer un correcto tratamiento ante una enfermedad es preciso determinar con toda la precisión y crudeza necesaria su diagnóstico; solo así podemos tener la certeza de que las medidas que se puedan proponer para tratar la misma son las adecuadas. Debó destacar que mi aparente pesimismo por el título de este apartado no es real, pues si tras más de treinta años en el servicio público todavía tengo la voluntad e interés de seguir investigando y proponiendo alternativas para la mejora de nuestras Administraciones Públicas, es porque creo en el futuro del servicio público y en la necesidad de que su actividad se desarrolle en los términos establecidos por los principios constitucionales de objetividad y eficacia.

Dicho lo anterior, en este momento voy a intentar resumir las principales causas, a mi juicio, de los problemas que actualmente afectan a nuestro empleo público en las siguientes notas:

a) Especialmente desde el año 1984, se ha desarrollado un proceso normativo y de gestión con el único objetivo de desterrar la profesionalidad y objetividad en el empleo público, de manera que nos encontramos ante un sistema caracterizado por la politización y clientelismo político y sindical, cuyo escaparate principal han sido los ámbitos de la selección y la carrera administrativa (procedimientos de provisión de puestos de trabajo $)^{2}$. Estas consideraciones que ya hemos manifestado en otros trabajos con anterioridad

1 Las opiniones contenidas en este artículo se realizan a título particular y no en mi condición de empleado público del Gobierno de Cantabria.

2 A este respecto nos hemos pronunciado en diversos trabajos, en concreto, podemos citar, entre otros: FONDEVILAANTOLÍN, J. (2015a), "Los procedimientos de provisión de puestos de trabajo: profesionalidad y objetividad versus clientelismo político y corrupción", Actualidad Administrativa, Wolters Kluwer. La Ley, núm. 7-8; también, (2015b), "El Principio de Transparencia: ¿Dónde está en el empleo público en España?", Aletheia: Cuadernos Críticos del Derecho, núm. 2, págs. 157-192. Monográfico: Ética de la Función Pública y Transparencia. http://www.liberlex.com/archivos/Transparencia FP JFA.pdf; asimismo, (2018a), "Repensar el diseño de los procesos selectivos en el empleo público: respuestas ágiles frente a las nécesidades inmediatas y fortalecimiento de la especialización de los órganos de selección", Revista Vasca de Gestión de Personas y Organizaciones Públicas, núm. 14 (especial), IVAP; además, (2018b), Manual para la selección de Empleados Públicos, 2. a edición (revisada y actualizada), Wolters Kluwer. El Consultor de los Ayuntamientos, Madrid, y finalmente, (2018c), Problemas y soluciones al empleo público actual: Una Valoración a los 10 años de la aprobación del EBEP, CEMCI - Granada.. 
son compartidas por un sector de la doctrina ${ }^{3}$, donde exponen directamente que: «Todo parece indicar que con la politización creciente y la proliferación de asesores y gabinetes políticos esto ya no es así, ya que los políticos parecen haber prescindido cada vez más del asesoramiento técnico de los funcionarios, liberándose de su influencia y, para garantizar supuestamente la ejecución de sus decisiones, han tratado de amarrar políticamente a los altos funcionarios. En definitiva, actualmente se funciona sobre la idea de que parece que los políticos han de tomar las decisiones libremente y por su cuenta y el papel de los funcionarios queda limitado a facilitar a posteriori la cobertura legal que sea necesaria (Nieto 2008). Asimismo, según los estudios empíricos disponibles, también entre los altos cargos de confianza política suelen predominar los burócratas profesionales, aunque crecientemente se va dando más cabida a los activistas de los partidos o expertos en comunicación política con escasa o nula cualificación profesional en los temas del departamento». Y, posteriormente, añaden la siguiente consideración: «Esta situación provoca la pérdida del respeto profesional por parte de los funcionarios al jefe político y su falta de expectativas profesionales, acompañada del desánimo por ver que sus jefes han conseguido por la vía de la política lo que ellos nunca van a conseguir por méritos profesionales, incitando así a los funcionarios a politizarse [...] Este proceso de "decapitación permanente" de las organizaciones del sector público se lleva por delante todo el capital directivo construido durante un largo periodo de tiempo», y todo ello, sin olvidar los peculiares procesos de funcionarizaciones masivas.

b) Como consecuencia de la politización citada, no se ha desarrollado una necesaria gestión profesional de recursos humanos y tampoco en la gestión de los servicios públicos. Destaca así la ausencia de regulación e implantación de un auténtico modelo de Personal Directivo, ajeno al ámbito político y vinculado exclusivamente a la evaluación de los resultados profesionales de su gestión, una cuestión esencial prevista el EBEP, pero pendiente de desarrollo tanto a nivel estatal como autonómico y local.

c) Asimismo, esa politización y clientelismo que han dirigido la gestión del empleo público, ha originado otro problema muy grave, en concreto, el acceso al empleo público mediante los denominados «procesos de consolidación o estabilización», o como los califica Jiménez Asensio «Aplantillamiento» de un enorme grupo de empleados públicos que han accedido al empleo público mediante unos sistemas de acceso sin las más mínimas garantías y que, además, en muchos casos con una clara vinculación política y sindical y dudosa cualificación profesional, lo que ha originado una pérdida de talento y profesionalidad en nuestras administraciones, y a su vez un fraude para el resto de los ciudadanos que han visto defraudadas sus expectativas de acceso al empleo público reconocido constitucionalmente en el art. 23.2. CE.

d) Además, con relación a los sistemas de provisión de puestos de trabajo, se han desarrollado grandes ejemplos de «imaginería e ingeniería jurídica» para alcanzar un alto nivel de colonización y manipulación política de la carrera administrativa de los empleados públicos, para ello, se han incorporado tres figuras básicas y muy útiles para los fines espurios que han sido uno de los fundamentos de la desbordante corrupción política que nos asola, en concreto, nos referimos a los procedimientos de provisión de puestos de trabajo mediante la libre designación, el concurso de méritos específico (en la práctica en muchos casos, una libre designación encubierta) y por último, la Comisión de Servicios, que constituye la primera fase a cumplir "adecuadamente» para poder después optar con garantías a los puestos de responsabilidad reservados a los otros dos procedimientos de provisión señalados.

Difícilmente vamos a poder renovar e innovar nuestras administraciones públicas si no se regenera y profesionaliza la función pública, es decir, en los puestos de trabajo de media y alta responsabilidad en las Administraciones Públicas su ocupación no puede estar dependiendo de la decisión caprichosa o interesada del órgano político de turno, pues la realidad de estos más de treinta años de experiencia, nos confirma que el criterio esencial para muchos de los nombramientos no ha sido ni el mérito ni la capacidad, sino simplemente la actitud del funcionario para ser «dócil y flexible» ante las pretensiones del órgano político. Además, para conseguir la cuadratura del círculo, nada mejor que el candidato fuera miembro o simpatizante del partido gobernante, lo que por sí mismo, no es malo, pero el problema es el uso de esas situaciones. Las reflexiones anteriores no suponen que estemos considerando como «politizados» a todos los funcionarios que desempeñan estos puestos por el sistema de libre designación, concurso específico u otros procedimientos, al contrario, muchos de ellos mantienen diariamente una lucha numantina en defensa de la objetividad y profesionalidad de su función, corriendo el riesgo permanente del cese discrecional.

3 OLMEDA GÓmEZ, J. A., PARRAdO DIEZ, S. y COLINO CÁMARA, C. (2017), Las Administraciones Públicas en España, $2 .^{\text {a }}$ edic., Tirant lo Blanc, Valencia. 
e) Todas estas situaciones han constituido el caldo de cultivo perfecto para el florecimiento y desarrollo de la corrupción, fenómeno que afecta a todas las administraciones públicas y a todos sus niveles. De manera que solo desvinculando la politización del empleo público e incorporando la exigencia de unos principios de ética pública a todos los empleados públicos, se podrá comenzar un nuevo camino ya despejado y acorde con el orden axiológico constitucional.

f) También quiero destacar que nos encontramos ante un momento muy importante para el futuro de nuestro empleo público, en concreto, me refiero a tres circunstancias que concurren y de gran importancia. En primer lugar, después de transcurrir 13 años desde la aprobación del EBEP, el mismo todavía está en gran medida pendiente de desarrollo. En segundo lugar, nos encontramos con un periodo de convocatorias de consolidación y estabilización de empleo temporal, procesos que merecen mi total crítica como ya he señalado en otros trabajos ya citados, y que pueden condicionar la eficacia de las Administraciones Públicas durante muchos años. Y, en tercer lugar, el hecho de que entramos en una década de renovación masiva del empleo público; pues hay un fenómeno imparable que es el envejecimiento de las plantillas de empleados públicos, lo que va a exigir que a medio plazo deberán producirse sustituciones masivas en la provisión de puestos de trabajo de responsabilidad y la incorporación de nuevas personas a las organizaciones, y, todo ello, sin que se hayan desarrollado plan alguno de transferencia de conocimiento, un elemento esencial en toda organización profesional.

Efectivamente, si algo ha caracterizado a nuestras administraciones públicas son las decisiones políticas a corto plazo, de manera que es difícil encontrar auténticos planes estratégicos de actuación a medio y largo plazo, lo que a su vez afecta directamente a las posibles políticas de recursos humanos. Así, no hay duda de que estamos en un momento esencial de cambios sociales de carácter radical que afectan por ejemplo a áreas tan variadas como las tecnologías de la información, robótica, biomedicina, entre otras, esto supone que las administraciones deberían estar reflexionando en estos momentos sobre los cambios necesarios en su organización y en especial de cuáles van a ser los nuevos puestos de trabajo que van a ser demandados por los servicios públicos en las próximas décadas para adaptarse a estos cambios y orientar los procesos masivos de renovación de plantillas que se avecinan en los próximos años ${ }^{4}$, de forma que los procesos de selección deberían adecuarse a estos nuevos tipos de necesidades, y que adquiere especial transcendencia en la selección de los futuros responsables de la dirección y gestión pública, pues la denominada «burocracia» se encuentra en una fase de necesaria y obligada transformación, lo que supone que los empleados públicos que accedan al empleo en los próximos años y que serán los responsables de dirigir la nave pública hasta más allá de mediados de este siglo, deben reunir las capacidades y aptitudes necesarias para la adaptación a los cambios de la sociedad y por ende de las administraciones, un simple ejemplo final, como destaca Ramió: ¿qué sentido tiene en estos momentos seguir incorporando de forma masiva personal administrativo (sin cualificación especial); me refiero a los cuerpos de auxiliares y administrativos, cuando resulta que las Tic y su uso por cualquier personal técnico superior cualificado hace innecesario su apoyo, cuestión diferente es limitar su incorporación a ámbitos de usuarios de sistemas o la atención personal a los ciudadanos (cuestión está cada vez más olvidada, como hemos comprobado en este periodo de la Covid19, olvidando algo tan importante como es la brecha digital de nuestra población, y en especial el contacto humano), que lógicamente durante un largo tiempo seguirán siendo necesarios, pero en unas condiciones y exigencias muy diferentes a las actualmente requeridas a estos cuerpos. Todo esto incide sobre una de las cuestiones de este trabajo, en concreto, la necesidad de revisar en profundidad los actuales procedimientos de selección.

En estos momentos resulta imprescindible y esencial una reflexión y reforma de nuestro marco normativo del empleo público y, además, la adopción de medidas estratégicas. Ha llegado el momento esencial que puede condicionar para las próximas décadas qué clase de empleo público va a servir a nuestra sociedad, pues una mala gestión de estas situaciones nos puede llevar a un negro futuro para los servicios públicos y que se continúe incumpliendo el mandato constitucional de un empleo público objetivo y eficaz, y por otro lado, incumplir el principio de la «Buena administración», que en estos momentos se está configurando,

\footnotetext{
4 RAMIÓ MATAS, C. (2019), "Inteligencia artificial y robotización reclaman un nuevo modelo de gestión del empleo público", Monográfico: La necesaria innovación en el empleo público local: problemas y alternativas; Wolters Kluwer. El Consultor de los Ayuntamientos, Madrid; GORRITI BONTIGUI, M. (2018), "Innovar en selección desde la evidencia empírica y las nuevas competencias", Revista Vasca de Gestión de Personas y Organizaciones Públicas, núm. 14 (especial), IVAP, del mismo autor, (2019), "Gestión planificada de vacantes: retos en Organización y Recursos Humanos", en Jorge FONDEVILA (dir.), Monográfico: La necesaria innovación en el empleo público local: problemas y alternativas; Wolters Kluwer. El Consultor de los Ayuntamientos, Madrid.
} 
tanto por la doctrina académica como por la jurisprudencia ${ }^{5}$, como uno de los ejes esenciales para la decisión y actuación de las administraciones públicas como principio autónomo y con una conexión al orden axiológico constitucional, de forma, que este resulta determinante para garantizar a los ciudadanos que las decisiones adoptadas en esta materia responden a criterios de razonabilidad, y desde luego la ausencia de una adecuada reflexión y planificación sobre sobre las necesidades organizativas y de personal de nuestras administraciones públicas para las próximas décadas, suponen una manifiesta infracción de este principio.

\section{LA SELECCIÓN EN EL EMPLEO PÚBLICO}

\subsection{Qué mejoras incorporó el EBEP al ámbito de los procedimientos de selección}

Debemos reiterar que, a nuestro juicio, los procesos de selección son una de las claves esenciales para la configuración de un administración objetiva, neutral y profesional, de manera que, si no se incorporan a los mejores, nos encontramos con un doble incumplimiento de los mandatos constitucionales, en primer lugar, los principios de igualdad, mérito y capacidad (art. 103.3 CE.) y, en segundo lugar, las exigencias del orden axiológico constitucional de una administración objetiva y eficaz. No se puede hablar de una correcta política de gestión de recursos humanos si no existe un adecuado procedimiento de selección, pues eso supone a la larga un lastre en el funcionamiento de la organización, y así lo constató la Comisión de expertos para la elaboración del EBEP6.

Dicho lo anterior, quiero destacar las aportaciones, si bien, con ciertos déficits importantes como señalaré posteriormente, ha realizado el TREBEP, así:

a) Resulta de gran importancia el reconocimiento legal de una serie de principios rectores de obligado cumplimiento de los procedimientos de selección, en concreto, nos referimos a las determinaciones del artículo 55. Estas previsiones distinguen dos áreas institucionales normativas:

1. Recordatorio de la aplicación de los principios constitucionales. Nos referimos a las previsiones de los artículos 23.2 y 103.3 de la CE que tienen como finalidad básica garantizar el acceso a las funciones y cargos públicos, con pleno respeto a los principios de igualdad, mérito y capacidad; ahora bien, esas previsiones tienen una necesaria conexión con el orden axiológico constitucional, en concreto, las previsiones de los artículos 1.1 y 103.1 de la CE, ya que, una selección correcta y ajustada a las

5 En este sentido resulta recomendable la consulta de los trabajos de PONCE SOLÉ, J. (2016), "La discrecionalidad no puede ser arbitrariedad y debe ser buena administración”, Revista Española de Derecho Administrativo (REDA), núm. 175, enero-marzo, y del mismo autor, (2019), La lucha por el buen gobierno y el derecho a una buena administración mediante el estándar jurídico de diligencia debida, Universidad Alcalá de Henares (UAH); y por otro lado, resulta imprescindible la consulta de la destacable sentencia de la Sala de lo contencioso-administrativo del Tribunal Supremo de 18 de diciembre de 2019 (rec. 4442/2018), que señala: «reafirmando que del derecho a una buena Administración pública derivan una serie de derechos de los ciudadanos con plasmación efectiva. No se trata, por tanto, de una mera fórmula vacía de contenido, sino que se impone a las Administraciones públicas de suerte que a dichos derechos sigue un correlativo elenco de deberes a estas exigibles, entre los que se encuentran, desde luego, el derecho a la tutela administrativa efectiva y, en lo que ahora interesa, sobre todo, a una resolución administrativa en plazo razonable»; y en la misma línea tenemos la sentencia del mismo Tribunal de 15 de enero de 2020 (rec. 3835/2018).

6 Informe de la Comisión para el Estudio y Preparación del Estatuto Básico del Empleado Público, INAP, Madrid, 2005, pág. 83 y ss., elaborado por encargo del MAP, que compartimos en su integridad y que podemos resumir en los siguientes términos:

a) Se ha comprobado la existencia de procedimientos selectivos que carecen de suficiente publicidad, transparencia, manifiestas discriminaciones, clientelismo político y favoritismo.

b) Se ha fomentado el uso de la contratación laboral, dado que la misma ha permitido una relajación en las garantías de la selección.

c) Igualmente, también se ha hecho un uso general del reclutamiento temporal, dado que este se ha realizado bajo unas mínimas garantías.

d) A lo anterior, debe añadirse la última perversión del sistema, que se ha manifestado por medio de los denominados procedimientos de consolidación, que en la práctica han supuesto integrar mediante pruebas o cursos simples a la condición de funcionario de carrera o personal laboral fijo a personas que en la mayoría de los casos su acceso ha sido como mínimo irregular.

e) También critica el uso inadecuado del procedimiento de concurso, dado que el mismo ha sido una expresión de la más amplia discrecionalidad, y además ha sido utilizado para la consolidación de las situaciones de temporalidad en el empleo público con una sobre valoración injustificada de los servicios prestados.

f) Por último, destacamos la crítica realizada a la composición de los órganos de selección y la ausencia de profesionalidad y especialización de los mismos, recomendando que su composición quede al margen de cualquier clase de «influencia o interferencia», sindical, partidaria o corporativa, su actuación debe ser absolutamente independiente. Asimismo, realiza una especial referencia al ámbito de las corporaciones locales, donde entiende la comisión que se ha producido un funcionamiento más problemático e irregular de los Tribunales de selección. 
exigencias constitucionales se constituye en uno de los fundamentos básicos para que se pueda dar cumplimiento a los mandatos constitucionales provenientes de los artículos 1.1 y 103.1 de la CE, en el sentido de conseguir la necesaria continuidad y calidad de los Servicios Públicos, en sentido amplio ${ }^{7}$.

2. Principios de carácter legal (TREBEP) o de naturaleza procedimental. Nos referimos a los principios recogidos en el apartado $2 .^{\circ}$ del artículo 55 que, como se puede apreciar, se centran más en las garantías de los sistemas selectivos y en la composición y actuación de los órganos de selección. Nosotros consideramos acertada esa diferenciación, por cuanto estos se configuran como instrumentos necesarios para poder garantizar el acceso al empleo público en condiciones de igualdad y respeto a los principios de mérito y capacidad. Destacando al respecto, en especial, la incorporación del principio de transparencia, que como veremos posteriormente, está desempeñando un papel esencial en la mejora de los procedimientos selectivos. Si bien, no podemos evitar una obligada critica al otorgamiento de la condición de «principio» a lo que es una simple técnica jurídico administrativa, en concreto, nos referimos a la «discrecionalidad técnica» ${ }^{8}$, cuestión esta que resulta de necesaria revisión.

Así, con relación a la situación anterior esto ha supuesto un claro avance en las exigencias legales de objetividad y profesionalidad en los procesos de selección.

b) La exclusión de representantes políticos y formalmente de organizaciones sindicales de los órganos de selección, aunque este último sector sigue interviniendo en los procedimientos, utilizando instrumentos en claro fraude legis, y tolerado por algunas autoridades y gestores públicos.

c) Ampliación del ámbito subjetivo de aplicación de los principios de aplicación a la selección previstos en el artículo 55.2 del TREBEP al ámbito del sector público, conforme establece la disposición adicional primera del TREBEP, si bien, esta cuestión fue objeto de un inicial rechazo por la Jurisdicción Social, aunque parece que el sentido común y la lógica aplicativa de las citadas previsiones legales ha vuelto recientemente al respecto ${ }^{9}$.

d) El artículo 61.2 párrafo segundo contiene una de las previsiones más desaprovechadas e ignoradas desde la aprobación del EBEP, que podían haber sido una clave esencial para la renovación de los procesos selectivos, por cuanto las mismas permiten una renovación integral de las obsoletas pruebas selectivas ancladas en un modelo decimonónico, que actualmente suponen una grave rémora para una innovación de los servicios públicos. Y no debe confundirse procedimiento de selección (oposición o concurso-oposición), con las pruebas a desarrollar en los mismos. Y ello, con independencia de que también resulte esencial desterrar de las fases de los concursos, la valoración del tiempo de servicios prestados, ya que, a mi juicio, la antigüedad nunca puede ser un mérito para acceder al empleo público, ni tan siquiera como complemento de otros, cuestión diferente es la valoración del desempeño del trabajo y su duración, tanto en el sector público como en el privado.

\subsection{Ausencias e incoherencias en el TREBEP}

El examen de lo ocurrido en estos 13 años desde la aprobación del EBEP nos confirma que mis críticas vertidas en anteriores trabajos ${ }^{10}$ se han visto confirmadas, por ello, estimo necesario realizar un examen de las ausencias e incoherencias detectadas en la regulación normativa del actual TREBEP sobre el desarrollo de los procesos selectivos, en concreto:

\subsubsection{La composición de los órganos de selección (artículo 60 TREBEP): una regulación inacabada}

a) A este respecto debemos comenzar por una cuestión de incoherencia en la regulación prevista en el artículo 60.2 del TREBEP, nos referimos a la ausencia de referencia alguna a la prohibición de participación

7 FONDEVILA ANTOLíN, J. (2000), Constitución y Empleo Público, Comares, Granada, págs. 84 y ss., y también 201 y ss.

8 FONDEVILAANTOLÍN, J. (2018c), op. cit., pág. 64.

9 FONDEVILA ANTOLÍN, J. (2019a), "La patente de corso otorgada por la jurisdicción social para la arbitraria contratación del personal de las sociedades públicas", Actualidad Administrativa, núm. 7-8, julio-agosto, 2019, y en Diario La Ley, núm. 9.450, Sección Temas de hoy, 5 de Julio de 2019, Wolters Kluwer; y también, (2019b), "El cuestionable amparo de la Jurisdicción Social y la arbitrariedad en el acceso al empleo en las sociedades públicas", Revista Vasca de Gestión de personas y organizaciones públicas, núm. 17. Aunque de forma reciente parece que el Tribunal Supremo, ha reflexionado sobre lo disparatado de sus primeros pronunciamientos, modificando su criterio al respecto, en concreto, nos referimos a las sentencias del Pleno de la sala de lo Social del Tribunal Supremo del 17 y 18 de junio de 2020, en unificación de doctrina.

10 FONDEVILAANTOLÍN, J. (2018c), op. cit., págs. 47 y ss. 
en los órganos selectivos del «personal laboral temporal». Efectivamente, recordemos que la finalidad del precepto, y así lo manifestó la propia Comisión redactora, era evitar cualquier clase de influencia o presión sobre los miembros de esta clase de órganos, pues bien, resulta incomprensible la ausencia de cualquier mención al personal laboral temporal, el cual tiene una situación de precariedad aún mayor que la de los funcionarios interinos. Esta cuestión ha generado múltiples incidentes en el proceso de composición de tribunales selectivos, si bien, parece que conforme nos han informado en encuentros con gestores de recursos humanos de diversas administraciones públicas, estos se han resuelto de forma razonable, es decir, aplicando el sentido común de los funcionarios responsables que no de las autoridades, realizando una interpretación extensiva de la finalidad del precepto, de manera que la conclusión era lógicamente su exclusión. Aunque, podemos indicar que aunque la literalidad del precepto es clara con relación a los funcionarios interinos, en algunos Ayuntamientos exigen a este personal formar parte de los tribunales e incluso su presidencia. Aún así, resulta claro, en mi opinión, que es urgente una revisión de esta previsión por parte del legislador, de manera que se eviten conflictos innecesarios en la gestión diaria y en especial, interpretaciones espurias.

b) Las presiones sindicales desarrolladas durante la tramitación parlamentaria del EBEP, como ya expuse en otro trabajo ${ }^{11}$, provocaron que desapareciera la mención expresa a la exclusión de las organizaciones sindicales que si estaba prevista en el proyecto de Ley. Pues bien, esto ha supuesto un conflicto permanente entre administraciones y estas organizaciones, resuelta desgraciadamente en gran parte de los casos mediante una solución torticera e hipócrita, en concreto, la consulta «informal» a estas organizaciones de las personas que obtendrían su «plácet» para formar parte de los órganos de selección, tras lo cual la administración nombra formalmente a las mismas, eso sí, no en representación de estas organizaciones sino como consecuencia de su profundo "proceso de valoración interno» que le lleva a concluir que estas personas son las más idóneas técnicamente e independientes para formar parte de los tribunales de selección.

Pero es más, también se han producido otras «invenciones» curiosas a este respecto, la verdad es que la lucha por seguir manteniendo el clientelismo sindical es atroz, y así, en otro trabajo recogía algunas de ellas tras un examen exhaustivo de convocatorias entre los años 2007 y $2010^{12}$, en concreto, representante sindical como observador con voz pero sin voto, representante sindical para el control de legalidad y similares; y esto no termina aquí, pues también los representantes políticos han logrado incorporarse de forma indirecta y fraudulenta a los procesos mediante la designación de observadores para la legalidad (repartiendo el número de observadores en función de la representatividad política) ${ }^{13}$. Desde luego, con estos ejemplos es imposible afirmar que estemos en presencia de órganos de selección profesionales e independientes, al contrario, seguimos sometidos al clientelismo político y sindical, pues como consecuencia de esos «acuerdos informales», los sindicatos también aceptan sin rechistar la incorporación de personas «afines» al órgano político que convoca el proceso selectivo, y esto es el día a día en nuestras administraciones, y en especial en las entidades locales.

c) Otra cuestión no resuelta por las previsiones del TREBEP, es la referida a la participación de los representantes de las Comunidades Autónomas en los órganos de selección de las entidades locales, y a este respecto, ya manifesté en otro trabajo mi opinión claramente contraria a su participación por exigencia de las previsiones del artículo 60.2 del TREBEP, y así se ha reconocido en algunas Comunidades Autónomas, pero por contra su aplicación no es generalizada, de manera que en Comunidades Autónomas tan importantes como Euskadi y Catalunya, estas siguen designando por medio de sus Escuelas de Formación (IVAP y EAPC) sus representantes. Estimo que nos encontramos ante una previsión normativa que debe ser objeto de una nueva reflexión, pues su actual redacción nos lleva a la conclusión de la exclusión de estos representantes, pero por contra un sentido lógico de aseguramiento de un funcionamiento objetivo y profesional de estos órganos nos lleva a considerar también la necesidad de su participación, pero el problema es que las actuales previsiones normativas son una fuente de conflicto, lo cual exige su revisión.

d) Una insuficiencia destacada en las previsiones del artículo 60.1 del TREBEP, es la ausencia de una regulación que incorporara una obligación expresa, declaración a mi juicio obligada, de que «todos» los miembros que compongan estos órganos deberán cumplir la obligación legal de «profesionalidad e imparcialidad», resultando destacable que tras pasados 13 años no se ha procedido a una actualización de las previsiones tanto del artículo 11 del Real Decreto 364/1995 (RGI) como del artículo 4 del Real Decreto 896/1991, para el ámbito local, y no digamos ya en las comunidades autónomas, donde tampoco se ha movido ningún cambio normativo al respecto.

11 FONDEVILA ANTOLÍN, J. (2018b), op. cit., págs. 134 y ss.

12 FONDEVILA ANTOLín, J. (2012), Manual para la selección de Empleados Públicos (1. a edición), Wolters kluwer. El Consultor de los Ayuntamientos, Madrid, págs. 184 y ss.

13 FONDEVILAANTOLÍ́N, J. (2012), op. cit., págs. 184 y ss. 
Así, con relación a la exigencia de «profesionalidad», ésta debe ser entendida como la posesión por parte de los miembros de los tribunales de la adecuada y suficiente formación sobre las materias que son objeto de examen en el proceso selectivo y, como ha señalado algún autor ${ }^{14}$, también una formación específica como técnico seleccionador o expertos en técnicas de selección, es decir, estamos en presencia del principio de especialización, elemento esencial de una adecuada selección, por cuanto no hay que olvidar que la actuación de estos se caracteriza por estar dentro de la esfera de la denominada «discrecionalidad técnica», que supone que las decisiones valorativas adoptadas no pueden ser objeto, en principio, de revisión jurisdiccional, y por ello, debe exigirse en contraprestación lógica la adecuada acreditación de la especialización de los miembros del tribunal, aunque esta "patente de corso» legalizada en nuestros procesos selectivos e igualmente en los concursos de provisión de puestos de trabajo parece tener afortunadamente las horas contadas como examinaremos posteriormente.

Esta cuestión, ya ha sido objeto de consideración por parte de nuestros tribunales, así, debemos destacar como la profesionalidad, la cual debe ser reconducida al principio de especialidad como parte del mismo, ha sido reconocida como elemento esencial en la configuración de los órganos de selección, y en este sentido ya se pronunció el Tribunal Constitucional en su sentencia 215/91 que señala al respecto: «...las áreas de conocimiento a efectos de la designación de los miembros de las Comisiones encargadas de resolver los concursos sean homogéneas respecto de las plazas objeto de concurso».

También, debemos reseñar entre otras la sentencia del Tribunal Supremo (sala de lo contencioso administrativo) de 13 de junio de 1989, y en especial, la sentencia de 5 de marzo de 2007 (rec. n. ${ }^{\circ}$ 508/2002), que considera que la especialización del Tribunal calificador impone que la mayoría de los miembros cuenten con la titulación afín a la plaza convocada y que además su actuación y presencia se mantenga en todas las pruebas, pero lógicamente, en todos estos pronunciamientos destaca el concepto «mayoría», que en estos momentos consideramos superado por las previsiones del TREBEP.

e) Finalmente, debemos referirnos a las previsiones de la Disposición adicional primera del TREBEP, que en general debe merecer un apoyo y reconocimiento pero que estimo se ha quedado a medio camino, y ello, por cuanto no ha incluido entre los preceptos de obligado cumplimiento por las entidades del sector público las previsiones del artículo 60 del TREBEP. Efectivamente, si queremos que los principios de igualdad, mérito y capacidad, proyección del principio básico de objetividad, informen toda la actividad administrativa, no se puede dejar de lado la composición de los órganos de selección y sus límites, de manera que en este amplio abanico de entidades constituidas dentro del proceso denominado «huida del derecho administrativo» pueden configurar sus órganos de selección, de manera unipersonal ( $p$. ej. director nombrado por designación política), con participación sin límites de las organizaciones sindicales, sin paridad de género y sin control alguno al respecto. Realmente esta es una brecha gravísima en el sistema de acceso al empleo público, pues, aunque estas entidades del sector público no reúnen las características esenciales y clásicas para ser calificadas como administraciones públicas en el sentido estricto, no por ello, pueden quedar fuera del marco general de los principios constitucionales aplicables a la selección de empleados públicos, en sentido amplio.

\subsubsection{El Acceso del personal laboral: un sistema demasiado flexible y con un claro riesgo de interferencias}

Debo comenzar señalando que el examen de las previsiones del artículo 61.6 y 7 del TREBEP, marca claramente la existencia de una diferencia sustancial en la determinación de los sistemas de selección a utilizar por las administraciones según el tipo de relación jurídica (funcionarial o laboral), así, nos encontramos, que para la selección de los funcionarios de carrera la utilización del sistema de "concurso», tiene un carácter excepcional y exige expresamente que el mismo se encuentre autorizado por una norma con rango de Ley, como ya he indicado en otros trabajos ${ }^{15}$, esta previsión me parece no solo correcta sino necesaria, dada la naturaleza y funcionalidad de este sistema de selección, pues este supone la declaración del derecho de uno o varios concursantes sobre otros, para obtener la adjudicación de una plaza que permite el acceso al empleo público, como consecuencia de haber obtenido una mayor calificación tras la correspondiente comprobación y valoración de los méritos aportados, previa convocatoria en la cual se determinan

14 GORRITI BONTIGUI, M. y TOÑA GÜENAGA, F. (2005), "El nuevo modelo de Organización y Recursos Humanos de la Administración General de la Comunidad Autónoma del País Vasco", Presupuesto y Gasto Público, núm. 41, págs. 266 y 267.

15 FONDEVILA ANTOLÍN, J. (2008), La selección y pérdida de la condición de empleado público, Atelier, Barcelona, pág. 159 y ss., y también, (2018b), op. cit., págs. 426 y ss. 
de forma previa cuáles son los méritos concretos que pueden ser sometidos a examen, entre estos pueden encontrarse servicios prestados, trabajos, experiencia, publicaciones, cursos realizados o impartidos, etc., lo que queda excluido de este sistema es la realización de cualquier clase de prueba teórico-práctica. De lo expuesto, se puede afirmar que este sistema mantiene la nota de la competitividad entre candidatos y preferencia por la puntuación total obtenida, si bien, esta clasificación responde a la mera evaluación de los méritos acreditados por los concursantes.

Ahora bien, este sistema presenta una clara posibilidad de vulnerabilidad, con relación al cumplimiento de los requisitos de igualdad, mérito, capacidad y objetividad, ya que ha sido habitual el hecho de que las administraciones hayan recurrido a este sistema para perseguir finalidades muy diferentes de las que legalmente son exigibles, por medio del establecimiento de méritos que responden no a las necesidades reales de las plazas convocadas, sino a perfiles previos de candidatos, en unas ocasiones porque estos han estado previamente desempeñando esos puestos de forma temporal, o bien, por ser unos candidatos conocidos del órgano político responsable de realizar la convocatoria correspondiente.

Pues bien, conforme determina el artículo 61.7 TREBEP, para el personal laboral no existe impedimento alguno para que las administraciones de forma discrecional decida utilizar el sistema de selección del «concurso», y esto supone una clara discriminación sin justificación alguna, ni operativa ni jurídica, al contrario, dada la naturaleza de este sistema y los riesgos que conlleva el mismo, a mi juicio, estamos en presencia de un «flexibilización» en los procedimientos de acceso al empleo público para el personal laboral, que responde claramente a las exigencias de clientelismo político y sindical, ya que, indudablemente, es mucho más fácil la instrumentalización espuria de este sistema que el de oposición, de manera que el acceso del personal laboral sigue siendo una puerta trasera y de menor exigencia profesional que la establecida para los funcionarios, y estimo que la alegación de que el acceso de los funcionarios conlleva el reconocimiento del derecho a la inamovilidad, no puede superponerse a los principios del artículo 103.3, de igualdad, mérito y capacidad, y menos aún a las previsiones del artículo 23.2 CE., que como ya he indicado en otros trabajos ${ }^{16}$ también resulta de aplicación al personal laboral. Por lo tanto, debo manifestar mi critica a esta previsión del TREBEP, ya que como he indicado no existe razón ni legal ni organizativa que justifique esta clase de decisión legislativa, y, por otro lado, reiterar mi preocupación por la continuidad de la posición del legislador a favor de la incorporación de personal laboral con un relajamiento de las garantías que deberían amparar a los ciudadanos que pretendan acceder al empleo público, seguimos como los mismos males y vicios.

Pero el tema no finaliza aquí, sino que además el citado artículo 61.7 TREBEP, incorpora una previsión muy preocupante, en concreto: «Las Administraciones Públicas podrán negociar las formas de colaboración que en el marco de los convenios colectivos fijen la actuación de las organizaciones sindicales en el desarrollo de los procesos selectivos», de manera, que si ya está resultando difícil la aplicación de las previsiones del artículo 60.2 TREBEP sobre la composición de los órganos de selección, la incorporación de una previsión de esta naturaleza tan sumamente imprecisa y ambigua, aunque a este respecto ya he aportado mi interpretación restrictiva en otro trabajo ${ }^{17}$, solo puede contribuir a abrir una puerta a la «interferencia sindical» en los procesos selectivos, con lo cual, nos encontramos con una clara conclusión, no hay duda de que estamos en presencia de una clara flexibilización y legalización de las interferencias en los procesos selectivos de personal laboral.

\subsubsection{Una puerta trasera de acceso inconstitucional: Disposición Transitoria $4 .^{a}$ TREBEP}

Tras un largo y muy discutido camino, al que me he referido en otro trabajo ${ }^{18}$ sobre los procesos de consolidación del empleo público temporal (contratos administrativos, funcionarios interinos y laborales temporales), consideraba que la lógica del orden normativo constitucional, la Jurisprudencia del Tribunal Constitucional y el sentido común nos inducían a considerarlos terminados, pero nos encontramos que el legislador, sin explicación alguna, reabre de nuevo un nuevo procedimiento «restringido» de «facto» para la consolidación de las nuevas contrataciones temporales realizadas con posterioridad a los ya referidos procedimientos de consolidación, siendo además el nacimiento de esas relaciones, en muchos casos, claramente irregular sino ilegal ${ }^{19}$.

\footnotetext{
16 FONDEVILAANTOLÍN, J. (2008), op. cit., págs. 105 y ss., y también (2018b), op. cit., págs. 39 y ss.

FONDEVILAANTOLÍN, J. (2018b), op. cit., págs. 623 y ss.

FONDEVILAANTOLÍN, J. (2008), op. cit., págs. 205 y ss.

19 Esta calificación y conclusión, no es solo propia, sino que también proviene del contenido de los informes tanto del Consejo Económico y Social (CES), en su Informe 3/2004, de 22 de diciembre, sobre La Temporalidad en el Empleo Público, y también el Informe del Defensor del Pueblo (2003), sobre Funcionarios Interinos y Personal Eventual: la provisionalidad y temporalidad en el empleo público.
} 
Lo anterior, resulta más sorprendente cuándo la Comisión de expertos ${ }^{20}$, en su Informe manifestó expresamente que: «...debe reducirse la temporalidad en el empleo público y consolidarse en mayor medida el empleo estable, una cosa es la "consolidación de los empleos" y otra muy distinta la subjetiva o particular de aquellos empleados que se han integrado en la administración por procedimientos excepcionales y escasamente competitivos, gozando de una situación de privilegio frente a otros posibles interesados», no podemos adoptar otra decisión más que adherirnos a esta opinión, y por ello, rechazar las previsiones de esta disposición transitoria cuarta del TREBEP, tanto por razones de lógica defensa de las exigencias constitucionales en el acceso al empleo público (23.2 y 103.3 CE.), como de la dudosa legalidad de la misma, conforme expongo en otros trabajos ${ }^{21}$.

\subsection{Algunas propuestas para una selección más profesional y objetiva}

\subsubsection{El imprescindible desarrollo normativo en el TREBEP de la implementación del Principio de Transparencia}

Este principio se ha configurado como unos de los ejes fundamentales que deben informar todas las actuaciones de las administraciones públicas, con un reconocimiento legal tanto en el ámbito europeo como en la legislación nacional. En el ámbito de la selección de empleados públicos (extensible también a la provisión de puestos de trabajo), reconocido legalmente en el artículo 55.2 b) del TREBEP, este principio, está destinado a desempeñar un papel esencial en este ámbito, de manera que se puede constituir en la clave de bóveda para el control de los procesos selectivos.

Efectivamente, como ya he indicado anteriormente la violación de este principio de transparencia conlleva, a mi juicio, una posible violación de derechos fundamentales, en concreto, las previsiones del artículo 24 CE., y en especial las previsiones del artículo 23.2 CE., pues la infracción de los mandatos que se deducen del principio de transparencia suponen una limitación del derecho constitucional para el acceso al empleo público en condiciones de igualdad, infracción que puede ser alegada en cualquier recurso tanto administrativo como jurisdiccional.

Si queremos cumplir las exigencias del orden axiológico constitucional sobre el empleo público, resulta imprescindible asumir que debe incorporarse toda una serie de controles y exigencias procedimentales en las actuaciones administrativas que garanticen que la selección de los empleados públicos se realice con pleno respeto a los principios constitucionales de igualdad, mérito y capacidad, y por ello, proponemos las siguientes medidas de lege ferenda, en concreto:

a) La necesidad de una modificación urgente del vigente marco normativo regulador de los procesos selectivos, donde se detalle y regule de forma expresa y precisa el régimen de funcionamiento de los órganos de selección, en el cual se determine, especialmente la obligación de publicitar los criterios de valoración, materiales y fuentes de información con las cuales va a operar el juicio técnico del órgano de selección, el procedimiento de acreditación de la motivación de las valoraciones de las pruebas y finalmente un régimen jurídico común y básico de «reclamaciones» ante los órganos de selección, pues en estos momentos como ya he expuesto en otro trabajo, esta posibilidad se encuentra limitada a las previsiones de las bases de convocatoria, y una regulación normativa al respecto podría evitar muchos conflictos administrativos y jurisdiccionales pues la misma podría suponer la posibilidad de habilitar un régimen específico previo a la vía ordinaria de recursos que solventaría la prolongación de conflictos en muchos casos innecesarios si existiera una auténtica transparencia.

Finalmente, resultaría adecuado que se regulara normativamente algo que por sí mismo no debería resultar necesario, pero a este respecto nos remitimos a los ejemplos jurisdiccionales referidos anteriormente, en concreto, el reconocimiento expreso (manual de instrucciones) de la obligación de los órganos de selección y de las administraciones públicas de facilitar el acceso a las actuaciones administrativas, pruebas o ejercicios tanto propios como ajenos y al expediente administrativo sin límites, salvo de los derivados de las exigencias legales en materia de protección de datos personales.

b) En segundo lugar, como consecuencia de todo lo expuesto y de la configuración legal del principio de transparencia estimo que podría resultar adecuado la aprobación de un «Reglamento básico regulador de la conducta ética de los órganos de selección», y ello, por cuanto como ya he señalado en anteriores apartados, la realidad es que la independencia de los miembros de estos órganos resulta en muchos casos muy cues-

20 Informe de la Comisión para el Estudio y Preparación del Estatuto Básico del Empleado Público, INAP, Madrid, 2005, págs. 84 y ss., elaborado por encargo del MAP.

21 FONDEVILAANTOLÍN, J. (2018b), op. cit., págs. 623 y ss. 
tionable, a título de ejemplo, nombramientos de «facto» por criterios sindicales o políticos o incluso un fenómeno no menos importante como son las conexiones de los preparadores de oposiciones con miembros de los órganos de selección que forman parte de su misma administración a cuyos procedimientos de selección concurren los opositores que han preparado (sic), lo que provoca situaciones de difícil ubicación en un código ético. Lógicamente, este código no debería limitarse a unas declaraciones generales de buenas intenciones, sino que debería regular especialmente una serie de obligaciones, compromisos y garantías expresas a cumplir por los miembros de los órganos de selección en su actuación, a lo que se debería añadir un régimen jurídico sancionador en el caso de su incumplimiento, pues a mi juicio, las declaraciones generales de intenciones sin el correspondiente establecimiento de consecuencias a su incumplimiento terminan convirtiéndose en papel mojado. En cuanto al posible carácter básico del reglamento propuesto entendemos que no existe inconveniente alguno, ya que estamos en presencia de un ámbito competencial material que gira sobre las figuras de la «abstención y recusación», las cuales se encuentran reguladas también con carácter básico en la Ley 40/2015 LRJSP, en sus artículos 23 y 24, por ello, estaríamos en presencia únicamente de una concreción normativa de un estatuto básico de los miembros de los órganos de selección, con una funcionalidad esencial por su directa conexión con el ejercicio de derechos fundamentales (artículos 14 y $23.2 \mathrm{CE}$ ).

\subsubsection{Reducción de la discrecionalidad técnica: el control sobre el contenido de la motivación de los órganos de selección}

En este punto debemos reiterar lo ya manifestado anteriormente, de que no estamos ante un principio jurídico, sino ante una simple técnica jurídica, que debe ser objeto de una necesaria revisión y delimitación sobre su alcance y que debe conectarse con el principio de especialización, el cual se encuentra incumplido de forma generalizada y mayoritaria en los procedimientos selectivos, basta con u simple examen, a este respecto. Así, la cuestión clave a este respecto debe centrarse en el establecimiento de un marco normativo que delimite y fije los criterios que deben adoptar los órganos de selección para la motivación de sus decisiones, ya que, precisamente, esa «motivación», en principio protegida por la discrecionalidad técnica, será la que posteriormente podrá ser objeto de revisión e incluso anulación. De todas formas, sobre temas conexos con esta cuestión volveremos posteriormente.

\subsubsection{Propuesta de una necesaria especialización de los órganos de selección según el tipo de ejercicios o pruebas a valorar}

Efectivamente, tal como ya he indicado en un apartado anterior, las previsiones del artículo 60.1 y en relación con el artículo 55.2 del TREBEP, exigen que «todos» los miembros de los órganos de selección acrediten que cuentan con formación específica (profesionalidad) en las materias objeto de las pruebas, por ello, a mi juicio, debe ser objeto de reflexión y de un adecuado desarrollo normativo la posibilidad de establecer una composición especializada y específica de los Tribunales pero por ejercicios o tipos de pruebas a desarrollar. Es decir, no parece razonable ni tampoco cumplir la exigencia de especialidad, el hecho de constituir un Tribunal, pongamos por caso para reclutar Arquitectos, que este compuesto en exclusiva por Arquitectos e Ingenieros de Caminos, Canales y Puertos, con lo cual, en principio, se daría perfecto cumplimiento al principio de especialidad, pero no se cumpliría en relación a un ejercicio (actualmente obligado en cualquier proceso selectivo), donde se exija un temario jurídico previo (Constitución, Estatutos de Autonomía, etc.), o lo mismo en sentido inverso, de forma que como puede quedar exento de control y considerarse que respeta el principio de «profesionalidad» que un licenciado en derecho valore un ejercicio práctico de un Ingeniero o Arquitecto, con lo cual entendemos que para evitar esta contradicción en la configuración de Tribunales y dar una adecuada respuesta al principio de especialidad, podría incorporarse unos Tribunales, de doble área o fase que respetaran en su composición realmente el principio de especialidad exigible a cada tipo de ejercicio.

\subsubsection{Propuesta de revisión de los tipos de pruebas utilizados en los procedimientos de selección}

El Estatuto Básico abre un amplio abanico de muy interesantes posibilidades en los apartados $2 .^{\circ}$ y $5 .^{\circ}$ del artículo 61, largamente demandado por la doctrina administrativista y la propia Comisión de estudio del proyecto de EBEP, pero esas posibilidades de innovación han sido objeto de un manifiesto «olvido» por parte de los gestores públicos y en especial, de los representantes de los intereses clientelares, pues la innova- 
ción suele ir reñida con los intereses espurios, de forma que como ya hemos expuesto en otros trabajos, es absolutamente necesaria una auténtica innovación completa y real, que no se encuentra en el ficticio debate sobre las herramientas o medios tecnológicos que se puede utilizar en el desarrollo de las pruebas selectivas, sino que este está en la necesaria reforma integral de los ejercicios o pruebas exigidas en estos procesos, pues las actuales resultan claramente inadecuadas y obsoletas, es decir, reclutamos empleados públicos para que presten sus servicios en el siglo XXI, con pruebas selectivas diseñadas en el siglo XIX, a esta situación para nada ayuda interpretaciones literalistas y ancladas en esos modelos obsoletos, como la recientemente formulada por el Tribunal Supremo (sala de lo contencioso administrativo), de 5 de noviembre de 2020 (rec. n. ${ }^{\circ}$ 5229/2018), que merece una crítica específica, pero que dados los límites de extensión de este trabajo no podemos realizar. Además, una profunda reforma de las pruebas supondría que resultará más fácil y simple el uso de medios electrónicos en los procesos selectivos sin que para su implementación resulte necesario forzar o infringir el marco legal vigente, a este respecto nos remitimos a un trabajo anterior $^{22}$, como se está produciendo en estos momentos en algunas administraciones.

Finalmente, debo señalar que una posible incorporación a la práctica de nuestras administraciones de estos nuevos tipos de pruebas y ejercicios supone la adopción de algunas medidas imprescindibles, aunque probablemente una decisión en ese sentido puede generar bastante reticencia en las mismas, vistos los usos desarrollados hasta este momento, así proponemos las siguientes:

a) Para una correcta implementación de unos nuevos tipos de pruebas y ejercicios, resulta necesario la creación de órganos especializados en técnicas de selección, con un carácter absolutamente técni$\mathrm{co}$, profesionalizado e independiente.

b) Estos órganos de selección deberían tener carácter permanente, y no tener una duración limitada temporalmente ad hoc.

c) Asimismo, deberían elaborarse protocolos formalizados de las técnicas de selección y criterios de evaluación a utilizar, con los correspondientes perfiles. Estos instrumentos deberían ser de uso común por todos los órganos técnicos de selección.

d) También debería revisarse la figura de los "cursos selectivos» posteriores a los procesos de selección, en mi opinión, su función puede resultar esencial especialmente en los grupos A1 y A2, para complementar adecuadamente los resultados obtenidos en las pruebas, y dotarles realmente de una función selectiva y no de u n mero complemento del proceso selectivo previo.

e) Quizás el mayor inconveniente puede ser un aparente aumento de los costos económicos de estos procesos, ahora bien, si se aplicaran las previsiones del artículo 61.4 TREBEP y se centralizara la celebración de los mismos, las economías de escala producidas abaratarían sin duda los costes, y además sería también adecuado realizar un estudio sobre el grado de mejora en los resultados de la selección, lo que se proyectaría directamente en la mejora de funcionamiento de los servicios públicos, es decir, en la mejora de la eficacia y eficiencia, lo que conlleva una reducción de costes de funcionamiento, que debería formar parte del estudio, pues lo que puede resultar un poco más caro durante la selección, se puede amortizar sobradamente durante la carrera administrativa del empleado público adecuadamente seleccionado.

\subsubsection{La necesidad de desarrollo de los órganos especializados y permanentes de selección: Una cuestión especialmente pendiente en las administraciones locales}

Es preciso destacar que el artículo 61.4 del TREBEP incorpora una previsión, que, a mi juicio, resulta totalmente acertada y más a la vista de las conclusiones formuladas en el apartado anterior, es cierto que esta regulación no resulta totalmente novedosa ya que existen antecedentes a este respecto en nuestras administraciones, si bien, su uso no ha tenido toda la intensidad que hubiera sido deseable, nos referimos, en concreto, a las Escuelas o Instituciones Autonómicas ${ }^{23}$ y en el propio INAP, por otro lado, nos encontramos con otro antecedente, que no es otro que las «Comisiones Permanentes de Selección» ${ }^{24}$, destacar a este

22 FONDEVILA ANTOLÍN, J. (2020), “La Administración electrónica y la celebración de ejercicios en los procesos selectivos: una necesaria innovación, pero con algunas dificultades legales para su implementación”, El Consultor de los Ayuntamientos, núm. 9 , Sección Rincón local, septiembre 2020, pág. 114, Wolters Kluwer.

23 Es el caso a título de mero ejemplo de la C. A. de Cantabria y el CEARC, C. A. Galicia y el EGAP, C. A. del País Vasco y el IVAP, entre otras.

24 Este órgano se encuentra regulado actualmente por la Orden del MAP de 3 de octubre de 2001. 
respecto que la composición actual de las mismas deberá sufrir una modificación como consecuencia de las previsiones del artículo 60 del TREBEP.

De todas formas entiendo que esta regulación ofrece una nueva oportunidad al conjunto de las administraciones públicas, para una correcta aplicación de las previsiones de los artículos 55 y 60 del TREBEP con relación a la selección de los empleados públicos, y en especial para las corporaciones locales de pequeño y mediano tamaño que son las mayoritarias en nuestro país, así, a través de convenios administrativos podrían estas encomendar la selección de su personal a estos Institutos o Escuelas siempre que estas hayan desarrollado adecuadamente su funcionamiento y medios materiales a las exigencias de unos adecuados procesos selectivos, esta actuación podría suponer que se alcanzase:

a) Un aumento de las garantías para conseguir el respeto adecuado a los principios de imparcialidad y profesionalidad (especialidad), ya que es difícil que en este tipo de municipios existan medios personales y especialmente cualificados por su propio tamaño, para poder configurar unos procesos y órganos selectivos que puedan cumplir adecuadamente los requisitos establecidos por el TREBEP.

b) Sería recomendable que la selección en las administraciones locales quedará centralizada, bien por medio de órganos dependientes de las Diputaciones Provinciales, lo que podría exigir un cambio normativo en una interpretación restrictiva, aunque si tomamos en consideración el cambio normativo incorporado en el artículo 36.2. c) de la LRBRL, modificado por la Ley 27/2013 LRSAL, a mi juicio no existe inconveniente alguno para que estas entidades locales asumieran la constitución y celebración de procesos selectivos de las entidades locales de forma centralizada mediante el correspondiente convenio administrativo, o bien, de las Escuelas de Función Pública Autonómicas. Esta posibilidad entendemos que resultaría muy discutida por las clásicas reticencias de los órganos políticos municipales ámbitos materiales de competencias.

c) Por otro lado, también podría resultar adecuado la creación de un Agencia o institución independiente común para todas las administraciones públicas, cuya función sería la selección de forma profesionalizada, al configurarse estas como instrumentos independientes y especializados en esta materia.

d) Asimismo, esta cesión podría suponer una mejora manifiesta de la eficacia y eficiencia económica en la gestión de los procesos selectivos, ya que en caso de ser asumidos directamente por las corporaciones locales puede suponer una carga tanto en gestión administrativa ordinaria como a los presupuestos municipales difícil de asumir.

\subsubsection{Una exigencia del Principio de igualdad y el Estado social: Las ayudas económicas para la preparación de los procesos selectivos}

Por último, estimo necesario realizar una reflexión sobre una cuestión esencial bajo las consecuencias de un Estado Social y su orden axiológico aplicable al respecto, conectado este al desarrollo efectivo del principio de igualdad, que se concreta en las previsiones del artículo 23.2 de la Constitución Española, es decir, la existencia de una verdadera igualdad efectiva, que permita que cualquier ciudadano aunque no cuente con los medios económicos suficientes pueda acceder a una preparación adecuada para su concurrencia a un proceso selectivo. Una nota que se aprecia en gran parte de los tradicionales cuerpos de las administraciones es una característica endogamia, que proviene claramente de esa diferencia de medios económicos que no permite concurrir en igualdad de condiciones de preparación y capacidades intelectuales a los procesos selectivos, por ello, estimo necesario la creación de unas políticas públicas de ayudas a aquellos ciudadanos que acredita objetivamente sus capacidades, no cuenten con el necesario soporte económico para preparar adecuadamente esta clase de procedimientos.

\subsection{Un breve examen de la jurisprudencia del Tribunal Supremo tras la aprobación del EBEP: Reducción de la discrecionalidad técnica y la incorporación del principio de transparencia.}

\subsubsection{Reducción de la discrecionalidad técnica: el control sobre el contenido de la motivación de los órganos de selección}

Estamos en presencia de uno de los grandes avances que se han producido en la evolución de nuestra jurisprudencia, tras la aprobación del EBEP, pues el control se extiende a uno de los núcleos esenciales en la actividad de los órganos de selección, de manera que además de exigir a estos la incorporación de su motivación, este juicio técnico debe ajustarse a unas exigencias de formalización, coherencia y solvencia, 
en este sentido resulta esencial la sentencia del Tribunal Supremo, sala de lo contencioso administrativo, de 18 de Noviembre de 2011, rec. 1920/2010, que señala: «La fase final de la evolución jurisprudencial la constituye la definición de cuál debe ser el contenido de la motivación para que, cuando sea exigible, pueda ser considerada válidamente realizada.

$\mathrm{Y}$ a este respecto se ha declarado que ese contenido debe cumplir al menos estas principales exigencias: (a) expresar el material o las fuentes de información sobre las que va a operar el juicio técnico; (b) consignar los criterios de valoración cualitativa que se utilizarán para emitir el juicio técnico; y (c) expresar por qué la aplicación de esos criterios conduce al resultado individualizado que otorga la preferencia a un candidato frente a los demás.

Son exponente de este último criterio jurisprudencial los recientes pronunciamientos de este Tribunal Supremo sobre nombramientos de altos cargos jurisdiccionales (STS de 27 de noviembre de 2007, recurso 407/2006), sobre concursos de personal docente universitario (STS de 19 de mayo de 2008, recurso 4049/2004) y sobre convocatorias del Consejo General del Poder Judicial para puestos en sus órganos técnicos (STS de 10 de octubre de 2007, recurso 337/2004)».

Además, el Tribunal Supremo también reconoce el derecho de los opositores a conocer la motivación de las calificaciones, debiendo indicarse el material y fuentes de información con las que va a operar el juicio técnico del órgano de selección. Así, los reiterados pronunciamientos del Tribunal Supremo, sala de lo contencioso administrativo, ${ }^{25}$ suponen una reconducción o limitación del alcance de la técnica de la discrecionalidad técnica, que no principio como incorrectamente es calificada por el artículo 55.2.d) del TREBEP, buscando alcanzar un mayor grado de garantías y por ello, ahora se impone que tales criterios de valoración o atribución de puntuación se fijen «antes» de la realización del ejercicio y además «se informe» a los aspirantes (Sentencia de la Sala de lo Contencioso-Administrativo del Tribunal Supremo de 20 de octubre de 2014 (rec. 3093/2013).

\subsubsection{La acreditación en vía de recurso administrativo y en el procedimiento judicial del desacierto de la actuación del órgano de selección mediante la práctica de una prueba pericial.}

Estamos ante una cuestión que durante mucho tiempo ha sido considerada «zona vedada a los tribunales», aunque es cierto que la sentencia del Tribunal Constitucional 86/2004, supuso el primer antecedente a este respecto ${ }^{26}$. Pues bien, el Tribunal Supremo ${ }^{27}$ ha procedido a la admisión de la utilización de la prueba pericial, y así considera que la presunción iuris tamtum sobre la valoración de los órganos de selección, aunque esta se asiente sobre informes o juicios técnicos y valorativos, también puede desvirtuarse, de forma que como señala Chaves García ${ }^{28}$, con cuyas conclusiones coincidimos, en estos momentos es posible desplazar y destruir la presunción de validez del juicio técnico pero bajo ciertas condiciones, que recoge la sentencia del Tribunal Supremo, sala de lo contencioso administrativo de 15 de junio de 2016 (rec. n. ${ }^{\circ} 2000 / 2015$ ), a cuya lectura nos remitimos, aunque ciertamente queda camino por recorrer, pues el control se detiene en el error manifiesto, con o sin la ayuda de pericia que lo constate.

\subsubsection{El Principio de Transparencia en los procesos selectivos: una exigencia ineludible.}

Debo reiterar las consideraciones que formule en otro trabajo ${ }^{29}$ con relación a este principio legalmente reconocido en el artículo 55.2 del TREBEP. A este respecto ya manifesté que era imprescindible la proyec-

25 Sentencia de 29 de enero de 2014 y que repiten luego las de 12 de marzo, 4 de junio y 24 de septiembre del mismo año.

26 Así, esta sentencia sostiene que la llamada discrecionalidad técnica no es sino una presunción iuris tantum, señalando: «ni el art. 24.1 ni el 23.2 CE, art. 23.2 art. 24.1 incorporan en su contenido un pretendido derecho de exclusión del control judicial de la llamada discrecionalidad técnica» (STC 138/2000, de 29 de mayo, FJ 4). Y es que «debe recordarse que, frente a la discrecionalidad técnica que ha de reconocerse a los órganos de selección en el marco de ese -prudente y razonable- arbitrio, nunca -excesivo- (STC 48/1998; FJ 7.a), las modulaciones que encuentra la plenitud de conocimiento jurisdiccional sólo se justifican en una «presunción de certeza o de razonabilidad de la actuación administrativa, apoyada en la especialización y la imparcialidad de los órganos establecidos para realizar la calificación». Una presunción iuris tantum, por cierto, de ahí que siempre quepa desvirtuarla -si se acredita la infracción o el desconocimiento del proceder razonable que se presume en el órgano calificador, bien por desviación de poder, arbitrariedad o ausencia de toda justificación del criterio adoptado-, entre otros motivos por fundarse en patente error, debidamente acreditado por la parte que lo alega (STC 353/1993).

27 Sentencias del Tribunal Supremo, Sala de lo contencioso administrativo, de 14 de enero de 2010 ; 16 de mayo de 2012 , rec. 1235/2011; 29 de enero de 2014; 14 de mayo de 2014, rec. 2075/2013 y la de 23 de febrero de 2016, rec.200/2015.

28 CHAVES GARCÍA, J. R. (2017), Vademécum de oposiciones y concursos, Amarante, Salamanca, págs. 187 y ss. y en el mismo sentido LAGUNA DE PAZ, J. C. (2017), "El Control judicial de la discrecionalidad administrativa", Revista Española de Derecho Administrativo, núm. 186, págs. 94 y ss.

29 FONDEVILAANTOLÍN, J. (2018b), op. cit., págs. 51 y ss. 
ción de este principio sobre la gestión del procedimiento selectivo en todas sus fases y en el funcionamiento de los órganos de selección, y que lo podíamos concretar en la obligación de que los criterios que se utilizan para la selección fueran claros y conocidos; que el proceso de designación de los miembros del órgano calificador fuera diáfano; que los actos de trámite, ya afecten directa o indirectamente al proceso, debían ser conocidos por los afectados; que todas las decisiones debían estar motivadas de forma adecuada y suficientemente y también añadí mi posición totalmente abierta y exigente de facilitar el acceso a los expedientes y pruebas, incluidas las de otros opositores. Como vamos a comprobar a continuación estas opiniones se han visto confirmadas de forma rotunda en los últimos años por la nueva línea jurisprudencia de reducción del alcance de la discrecionalidad técnica.

A la vista de lo expuesto no hay duda de que estamos en presencia de un nuevo eje esencial a tomar en consideración en el desarrollo y regulación normativa de los procesos de selección y, también en la provisión de puestos de trabajo como veremos posteriormente. De hecho, no tengo duda de que uno de los motores del cambio descrito en el apartado anterior referido a la nueva doctrina del Tribunal Supremo sobre la discrecionalidad técnica, tiene su origen en la incorporación de este principio a nuestro ordenamiento jurídico, y en este sentido podemos destacar la sentencia del Tribunal Supremo de 11 de mayo de 2016, rec. 1493/2015, que señala al respecto: «Debe decirse que ese principio de publicidad, en su formulación más genérica, está ligado a otros mandatos constitucionales como lo son el derecho fundamental de tutela judicial efectiva del artículo 24 de la Constitución (CE) y el principio de objetividad que para toda actuación de la Administración pública dispone el artículo 103.1 del propio texto constitucional. Y por eso mismo conlleva, entre otras cosas, tanto la necesidad de que toda actuación administrativa sea transparente en los hechos, criterios y razones que determinen sus decisiones, pues solo así es posible el control que demanda el derecho de tutela judicial efectiva; como también que esos criterios estén establecidos con anterioridad a su finalización cuando de procedimientos competitivos se trate, porque de esta manera es como queda conjurado con las debidas garantías el riesgo del favoritismo individual (contrario al principio de objetividad) que se produciría si los criterios de valoración de los aspirantes fuesen definidos una vez realizadas esas pruebas competitivas».

La traslación de este principio a los procedimientos selectivos se puede apreciar de forma más clara y precisa en dos ámbitos materiales:

a) El Derecho a conocer la motivación de la calificación o valoración de las pruebas por los órganos de selección, (Sentencias del Tribunal Supremo, sala de lo contencioso administrativo, de 26 de junio de 2014, rec. 2399/2013, 10 de diciembre de 2014 (rec. 3754/2013), 13 de julio de 2016, rec. 2036/2014) y la de 22 de noviembre de 2016, rec. 4453/2015.

b) El Derecho de acceso al expediente administrativo, documentación y actuaciones, (Sentencia del Tribunal Supremo de 16 de diciembre de 2015 (rec. 2803/2014), también la STS de 18 de mayo de 2015 (rec.3589/2013).

\section{UNA CARRERA ADMINISTRATIVA PROFESIONAL O POLITIZADA: LOS PROCEDIMIENTOS DE PROVISIÓN DE PUESTOS DE TRABAJO}

Por mi experiencia personal, en el desarrollo diario de las tareas asignadas a los funcionarios públicos, lo más determinante es el desempeño de su concreto puesto de trabajo, de manera que el concepto de carrera administrativa, salvo por los efectos económicos de la consolidación de un grado personal, pasa a un segundo plano, resultando que lo esencial para los mismos es la provisión de puestos de trabajo pues el concreto puesto a desempeñar va a condicionar su quehacer diario y además tiene un efecto directo sobre sus retribuciones, recordemos la importancia que el complemento específico tiene a este respecto.

Por otro lado, es preciso tener en cuenta que tanto para la carrera administrativa como para la provisión de puestos de trabajo el TREBEP reconoce la aplicación directa de unos principios básicos aplicables a ambas instituciones (artículos 16.2 y 78.1), en concreto, los de igualdad, mérito y capacidad, residenciados a su vez en el artículo 23.2 (CE), a los que debemos añadir a mi juicio por su importancia en la configuración final de su régimen jurídico el de transparencia. El propio Tribunal Constitucional ha tenido ocasión de pronunciarse en reiteradas ocasiones sobre su proyección a lo largo de toda la carrera funcionarial, pudiendo citar por todas la STC de 25 de Febrero de 2008, que señala: También hemos dicho que el art. 23.2 CE «actúa no sólo en el momento del acceso a la función pública, sino también durante la vigencia de la relación funcionarial y, por tanto, es aplicable a los actos relativos a la provisión de puestos de trabajo (SSTC 75/1983, 15/1988 y 47/1989)». 
Asimismo, el TREBEP (artículos 16 y 17) configura la carrera administrativa en dos clases (vertical y horizontal), siendo la nota común de ambas su conexión a un concreto concepto retributivo (Grado o complemento de carrera respectivamente), si bien, el sistema de acceso a estos es diferente, en el caso de la carrera vertical es por medio de la provisión de un concreto puesto de trabajo y en la carrera horizontal es la valoración de su trayectoria profesional, calidad de su trabajo, conocimientos y evaluación de desempeño. Además, es preciso destacar que el desarrollo de la carrera horizontal sigue siendo una tarea pendiente en muchas de nuestras administraciones, es cierto que existen algunos casos pero no podemos hablar de generalidad $^{30}$. No vamos a negar la importancia de la carrera administrativa, pero a mi juicio, la clave para un funcionamiento profesional, es decir, objetivo, independiente y transparente es la incorporación al régimen jurídico funcionarial de un sistema de provisión de puestos de trabajo que respete el orden constitucional y sus principios (igualdad, mérito y capacidad), ya que además no se puede olvidar que con independencia del tipo de carrera administrativa a la cual se haya adherido el funcionario, lo que es invariable y común a ambos tipos es el derecho de acceder a un puesto de trabajo y por lo tanto, los procedimientos de acceso constituyen el eje fundamental de la vida administrativa de los funcionarios.

Dicho lo anterior, debo reiterar lo ya indicado en otros trabajos ${ }^{31}$, la vida profesional de los funcionarios desde el año 1984 pivota en torno al puesto de trabajo, y es aquí donde se han desarrollado grandes ejemplos de «imaginería e ingeniería jurídica» para alcanzar un alto nivel de colonización y manipulación política de la carrera administrativa de los empleados públicos, para ello, se han incorporado dos figuras básicas y muy útiles para los fines espurios que han sido el fundamento de la corrupción política, en concreto, nos referimos a la libre designación, el concurso de méritos específico utilizado de manera fraudulenta (en la práctica una libre designación encubierta).

\subsection{Examen de los «problemáticos» procedimientos de Provisión de Puestos de Trabajo}

En este punto vamos a realizar un examen general de los principales problemas que presentan los dos procedimientos de provisión de uso más común y general, y asimismo indicaremos las propuestas alternativas o complementarias a este régimen jurídico.

\subsubsection{Provisión de Puestos de Trabajo por Libre Designación}

De acuerdo a lo ya expuesto en nuestras consideraciones previas, los procedimientos de provisión de puestos de trabajo en los niveles superiores y medios de responsabilidad en la gestión de nuestras administraciones han resultado perniciosos, nefastos y de lo más inadecuado para dar cumplimiento a las exigencias constitucionales (artículo $103 \mathrm{CE}$ ), en la consecución de una Administración al servicio de los ciudadanos, ya que, uno de los pivotes esenciales de toda organización para desarrollar las funciones legales y, especialmente, controlar el respeto al Estado de Derecho, son sus recursos humanos, y, es triste destacar como la aplicación de esta figura, es cada vez más habitual en muchas administraciones autonómicas y locales de forma generalizada convirtiéndola casi en el procedimiento «ordinario» para todos los puestos de jefaturas de negociado, sección, servicio y similares.

Así, podemos destacar varias Comunidades Autónomas donde el uso de Libre designación de forma indiscriminada y generalizada sigue siendo la nota característica, ante una posición de perfil del Tribunal Constitucional y de la oposición política (aunque claro suele resultar habitual que este sistema sea del agrado de todos los grupos políticos), y además, santificado mediante su imposición en las correspondientes leyes de Función Pública en casi todos los puestos de trabajo reservados a funcionarios de carrera con una mínima responsabilidad en materias tan esenciales como el asesoramiento jurídico, técnico y especialmente el del control económico y presupuestario, entre otros podemos destacar los ejemplos de las Comunidades

30 En este sentido destaca la Ley 3/1985, de 26 de diciembre, de Ordenación de la Función Pública de la Administración del Principado de Asturias (art. 49 bis y ss.) y el Decreto 37/2011, de 11 de mayo, por el que se aprueba el Reglamento de la carrera horizontal de los funcionarios de la Administración del Principado de Asturias. También, rápidamente en el año la Comunidad Autónoma de Extremadura lo incorpora y así se mantiene en el artículo 105 de la Ley 13/2015, de la Función Pública Extremadura y ha sido objeto de aplicación desde hace años, en otras Comunidades Autónomas se ha reconocido, pero está pendiente de implementación como por ejemplo Comunidad Valenciana, Castilla-La Mancha, Galicia.

31 FONDEVILAANTOLÍN, J. (2007); "Provisión de puestos de trabajo y movilidad", en Estatuto Básico del Empleado Público (dir. ORTEGA ÁLVAREZ), Wolters Kluwer. La Ley. El Consultor de los Ayuntamientos, Madrid, y también (2015a), op. cit., y (2015b), op. cit. 
Autónomas de Extremadura, Castilla-La Mancha, Principado de Asturias, Generalitat Valenciana entre otras y que además ha recibido el beneplácito del Tribunal Constitucional en su reciente Auto de 18 de Octubre de 2016, el cual inadmite la cuestión de inconstitucionalidad planteada por la Sala de lo Contencioso Administrativo del TSJ de Galicia contra la Ley de Función Pública de Galicia que establecía la utilización de la libre designación para todas las jefaturas de servicio, es decir, se convertía la excepción en regla, y el Tribunal Constitucional se ha limitado a declarar que la comunidad autónoma tiene competencia para legislar en materia de función pública, el pronunciamiento resulta como mínimo escuálido.

Dicho lo anterior, tenemos que formularnos una pregunta, ¿ha aportado alguna mejora a esta situación la regulación aprobada por este Estatuto Básico?. Pues bien, intentaré dar una respuesta a la misma. De entrada, como ya manifesté en otro trabajo ${ }^{32}$, creo que no ha mejorado en nada la anterior situación, ya que lo primero que se puede constatar es que su régimen jurídico es prácticamente idéntico a las previsiones de la derogada LMRFP, si bien, si puede apreciarse dos pequeñas modificaciones, pero cuya valoración es muy discutible.

Así, en primer lugar, nos encontramos con una modificación de los supuestos que habilitan la utilización de este procedimiento, por un lado, han desaparecido las menciones concretas a los puestos de trabajo de la AGE, lo cual es absolutamente lógico, dado que estamos en presencia de un Estatuto Básico y común al conjunto de las administraciones públicas. Y, por otro lado, se incorpora de forma expresa el concepto ya utilizado tanto por la Jurisprudencia como por la doctrina como hemos observado de la «confianza», de todas formas, la cuestión clave se encontrará en la aplicación realmente excepcional de esta figura y la interpretación que se quiera dar a estos conceptos jurídicos indeterminados, pues en función de ella, el ámbito de aplicación puede crecer de forma desmesurada. De todo esto podemos deducir que las cosas continúan de la misma manera que en el anterior marco normativo de la LMRFP, y no se aporta solución alguna a los problemas que detecto la Comisión de expertos, al contrario, dada la indefinición de los supuestos nos podemos encontrar con una auténtica inflación de puestos reservados al procedimiento de provisión de la libre designación.

La única novedad que, a nuestro juicio, resulta realmente interesante es la previsión del apartado tercero del artículo, que recoge una de las propuestas formuladas por la Comisión de expertos, si bien, como en otros contenidos de este Estatuto, se queda a medio camino, es un quiero y no puedo, ya que esa previsión no es de obligatoria aplicación, nos estamos refiriendo a la posibilidad de recabar la intervención de especialistas o expertos para que informen sobre la idoneidad de los candidatos concurrentes. Así, puedo afirmar que esta medida si supondría un enorme avance en la mejora de la eficacia y eficiencia de la administración pública al estar seleccionando a los más idóneos, lo que supone acercar la figura de la libre designación a los principios de mérito y capacidad, de los cuales como ya ha señalado Morell Ocaña ${ }^{33}$, se encuentra muy lejos y demasiado cerca del clientelismo político. Lo realmente decepcionante es que cuándo se decide por parte del legislador incorporar medidas recomendadas por una comisión de expertos, la cual ha hecho previamente un diagnóstico, a mi juicio, totalmente acertado, al final se aprecia una falta de coraje o decisión política real de dar solución a los manifiestos problemas generados y contrastados. Tras más de veinte años de uso de la figura de la libre designación, parece más bien, que no interesa a nadie prescindir de una fórmula que garantiza adhesiones y confianzas políticas, olvidando que como declaraba el Tribunal Constitucional en su STC 10/1989: «la facultad de libre designación no atribuye al órgano de decisión una especie de poder omnímodo a fin de decidir cómo tenga por conveniente, con olvido de que el servicio del interés público es la esencia y el fundamento del ejercicio de toda potestad administrativa». Es decir, el interés público no puede ser olvidado ni por la administración ni tampoco por el propio legislador, a la hora de ofrecer una adecuada solución a los problemas previamente detectados y más, cuándo los propios expertos han formulado expresamente una recomendación para su solución. Por lo que parece que lo recomendable hubiera sido el establecimiento de este mecanismo de forma obligada dentro del procedimiento de libre designación.

Así pues, qué sentido tiene la libre designación, salvo la pura y dura «confianza política», es decir, estamos actualmente más cerca de la figura del personal eventual (artículo 8.2 d) del Estatuto Básico), que de una fórmula de provisión de puestos de trabajo para funcionarios de carrera que debe estar sometida a los principios de objetividad (imparcialidad), igualdad, mérito y capacidad, y con ello, garantizar un funcionamiento objetivo y eficaz en la satisfacción del interés público.

32 FONDEVILAANTOLÍN, J. (2007); op. cit., págs. 611 y ss.

33 MORELL OCAÑA, L. (2001), "Dirección de la Administración Pública por el Gobierno y garantías de imparcialidad administrativa”, Revista de Administración Pública, núm. 156, págs. 53 y ss. 
Ya expuse las razones que justificaban, a mi juicio, una crítica clara y contundente al mantenimiento de este instrumento de provisión de puestos de trabajo en la Ley 7/2007, de 12 de abril del Estatuto Básico del Empleado Público (EBEP) ${ }^{34} \mathrm{y}$, la verdad sea dicha, la realidad ha confirmado todos mis temores y reticencias, ya que nos encontramos ante uno de los instrumentos legales más perniciosos y nocivos, que ha sido instrumento fundamental para que no se haya conseguido un ético, eficaz y objetivo funcionamiento de las administraciones públicas. Además, la politización de las carreras administrativas de los funcionarios, resultando la figura de la libre designación su principal arma, ha sido una de las claves de la masiva y rampante corrupción en la gestión pública, y en este sentido debemos destacar entre otros la opinión de Núñez Pérez (expresidente del Tribunal de Cuentas) ${ }^{35}$, que considera que el germen de la corrupción se encuentra en la generalización de los puestos de libre designación entre los funcionarios de altas responsabilidades, también resulta ilustrativo al respecto la crítica de Chaves García ${ }^{36}$, y con relación a la situación de la Administración Local, Sosa Wagner ${ }^{37}$ destacaba el grave peligro que suponía la politización de la función pública mediante el uso de la libre designación frente los principios de mérito y capacidad, opiniones todas ellas que comparto totalmente.

\subsubsection{Un poco de aire fresco: La doctrina del Tribunal Supremo sobre los controles en las convocatorias, motivación y cese en los procedimientos de libre designación}

Debo llamar la atención sobre la importancia que en estos momentos de control político espurio está teniendo la doctrina del Tribunal Supremo, ya que, los pronunciamientos que están produciendo especialmente desde el año 2012 suponen un dique de contención ante los desmanes de las administraciones en la utilización del procedimiento de la libre designación.

A este respecto, podemos establecer tres ámbitos materiales diferentes en sus declaraciones que alcanzan ${ }^{38}$ :

a) La «excepcionalidad» en la utilización de este sistema de provisión. Por un lado, el establecimiento de límites al concepto de «excepcionalidad» en la utilización de este sistema de provisión, aunque nuestra clase política autonómica, con la bendición del Tribunal Constitucional (Auto de 18 de octubre de 2016), ha encontrado la fórmula mágica para evitar interferencias del Tribunal Supremo, y que no es otra que incorporar a sus Leyes de Función Pública una ampliación sin límite de la aplicación de la libre designación (Jefes de servicio e incluso unidades administrativas ${ }^{39}$ ), de manera que lo que debería ser excepcional, conforme la doctrina del Tribunal Supremo, se convierte por decisión política e interesada en norma general.

Así, la Jurisprudencia (STS, Sala de lo Contencioso, sección 7. ${ }^{\text {a }}$, de 21 de mayo de 2012, Rec. n. ${ }^{\circ}$ 5754/2010) declara ya bajo la vigencia del Estatuto Básico del Empleado Público, aprobado por Ley 7/2007, de 12 de abril, que la elección del procedimiento de libre designación para la provisión de determinados puestos de trabajo incluidos en la Relación de Puestos de Trabajo del personal funcionario de la Administración y de sus organismos y entes públicos dependientes, «exige una motivación específica, una justificación concreta de las razones por las que, a partir de los cometidos propios del puesto de trabajo, concurren los requisitos legalmente establecidos para que se provea por este procedimiento de libre designación; justificación que es necesaria desde el momento en que el Estatuto Básico del Empleado Público no altera la consideración que merecen el concurso y la libre designación como mecanismos de provisión de puestos de trabajo». El concurso, dice la sentencia, es el modo normal de provisión, mientras que la libre designación es la excepción, y «como toda excepción a la regla ha de ser interpretada estrictamente y la Administración, cuando quiera servirse de ella por entender que el puesto de trabajo es de especial responsabilidad o de confianza, deberá justificarlo de forma específica».

34 FONDEVILAANTOLÍN, J. (2007), op. cit., págs. 611 y ss.

35 Nos estamos refiriendo a la Conferencia impartida por D. MANUEL NÚÑEZ PÉREZ (expresidente del Tribunal de Cuentas), en la Universidad de Oviedo (Facultad de Derecho) en el año 2010, con motivo de la celebración de la festividad de San Raimundo de Peñafort, titulada El Comportamiento ético en la gestión pública.

36 CHAVES GARCIA, J. R. (2009), "La sombra del cese fulminante sobre el letrado público de libre designación", en el blog: https://delajusticia.com/2009/09/19/la-sombra-del-cese-fulminante-sobre-el-letrado-publico-de-libre-designacion/.

37 SOSA WAGNER, F., nos referimos al artículo publicado en la Sección de Opinión, del Diario el Mundo, de 30 de abril de 2007 , con el título de "Nuevo desalojo del Estado: secretarios e Interventores".

${ }_{38}$ Para la recopilación de la jurisprudencia citada hemos seguido el trabajo de SANGÜESA CABEZUDO, A. M. ${ }^{a}$ (2016), "Nombramientos de libre designación en la Administración General del Estado. Nombramientos discrecionales. La diferencia entre uno y otro supuesto a la luz de la jurisprudencia", Actualidad Administrativa, núm. 12.

39 Un ejemplo lo tenemos en el artículo 121 de la Ley 13/2015, de 8 de abril, de Función Pública de Extremadura. 
Por ello, el Tribunal Supremo exige una justificación individualizada y para que esta pueda ser considerada suficiente, y que la decisión administrativa no deba ser calificada como arbitraria y no discrecional, «es preciso describir las concretas circunstancias y cometidos concurrentes en el puesto de que se trate que permitan valorar si es o no de apreciar en el mismo el carácter directivo o la especial responsabilidad de los que depende la validez del sistema de libre designación, y que no bastan a estos efectos fórmulas estereotipadas o la mera denominación aplicada al puesto» (Sentencia del Tribunal Supremo de 13 de noviembre de 2012 (rec. n. ${ }^{\circ}$ 5887/2011).

Así se ha entendido, cuando «no se ha acreditado la exigencia de esa especial responsabilidad, más allá de las funciones directivas que le atribuye la normativa reglamentaria», y "aparece como razonable y compatible con los principios de mérito y capacidad que, salvo las excepciones legalmente previstas, rigen también en la provisión de destinos entre quienes tienen capacidad acreditada para cubrir los correspondientes puestos, sin que el hecho de buscar una complicidad en las líneas rectoras de la Administración correspondiente sea motivo suficiente, pues el principio de jerarquía es suficiente garantía de tal correspondencia» (STS, Sala de lo Contencioso, sección 7. a del 19 de mayo de 2016, Rec. n. ${ }^{\circ}$ 1214/2015). La determinación de si los concretos cometidos funcionales asignados a un determinado puesto de trabajo encarnan o no la especial responsabilidad que justifica la libre designación «es una tarea de calificación jurídica, ajena al espacio de la discrecionalidad y, por ello, revisable jurisdiccionalmente» (Tribunal Supremo, Sala Tercera, de lo Contencioso-administrativo, Sección 7. a , Sentencia de 30 mayo 2013, Rec. n. ${ }^{\circ}$ 2398/2012). Por lo tanto, es a la Administración a la que corresponde justificar, en los términos que la jurisprudencia establece, las singulares razones por la que optó por dicho sistema en cada puesto.

Esta línea jurisprudencial que defiende la normalización del sistema de concurso, frente a la excepción, señala que «la confianza no puede ser el único o principal elemento caracterizador de los puestos reservados a los funcionarios de carrera que tienen establecido el sistema de provisión de libre designación, por ser ello contrario al principio de profesionalización proclamado en nuestro actual ordenamiento administrativo y, también, por tener tal elemento su normal aplicación en la diferente figura del personal eventual» (STS, Sala Tercera de lo Contencioso administrativo, Sección 7. ${ }^{a}$, del 24 de noviembre de 2010, Rec. n. ${ }^{\circ}$ 5140/2007)

Por lo tanto, resulta inexplicable la tolerancia del Tribunal Constitucional con algunas Comunidades Autónomas, al permitir la transformación del sistema de provisión de la libre designación en un instrumento de generalizada utilización, perdiendo su característico carácter de «excepcional», debe ser que aplican con carácter general lo que dentro de su casa se práctica con carácter habitual.

b) El procedimiento de adjudicación y la motivación de la misma. El segundo ámbito material que examina el Tribunal Supremo hace referencia al procedimiento de adjudicación y la motivación de la misma, así, el Tribunal Supremo (STS Sala Tercera, de lo Contencioso-administrativo, Sección 7. a, Sentencia de 4 febrero 2016, Rec. n. ${ }^{\circ} 665 / 2014$, resume las notas definidoras de estos nombramientos:

1. La libre designación implica una valoración por parte de la administración convocante, junto a la comprobación del cumplimiento de los requisitos establecidos, un juicio de idoneidad y confianza respecto de la persona a designar.

2. La libre designación supone en su apreciación «una evidente connotación de discrecionalidad o, si se prefiere (...) un cierto margen de libertad». Así, pues, si estamos en el ámbito de la discrecionalidad, no cabe arbitrariedad en su ejercicio y es imprescindible una motivación suficiente según el art. 54 de la Ley 30/1992, de 26 de noviembre, de Régimen Jurídico de las Administraciones Públicas y del Procedimiento Administrativo Común. Motivación cuya suficiencia deben controlar los tribunales y examinar si el ejercicio de la discrecionalidad que la Ley ha concedido ha tenido lugar sin arbitrariedad y con sometimiento a los fines para los que le dio la potestad ejercitada. A estos últimos efectos, una jurisprudencia constante incluye dentro del control judicial de la discrecionalidad administrativa el examen de los hechos determinantes de la actuación cuestionada.

3. Por lo tanto, la motivación no podrá quedar limitada a lo que literalmente establece el art. 56.2 del RGI, es decir, el cumplimiento por el candidato elegido de los requisitos y las especificaciones exigidos en la convocatoria y la competencia para proceder al nombramiento, en este sentido sentencia del Tribunal Supremo, Sala Tercera, de lo Contencioso-administrativo, Sección 7. a, de 30 septiembre 2009, Rec. n. ${ }^{\circ} 28 / 2006$.

Ese deber de motivación específico se extiende incluso al supuesto en el que el puesto quede desierto, en cuyo caso, la Sala Tercera exige una justificación razonada que atiende al caso concreto y a las características de los puestos. Así, señala: «... tiene razón la demanda cuando pone de relieve la insuficiencia de la 
única motivación que se encuentra en el expediente de la declaración como desierto del puesto núm. 15 de los convocados el 10 de julio de 2013. Decir que, de los dieciséis solicitantes, todos los cuales reúnen los requisitos exigidos, ninguno reúne las condiciones de idoneidad y confianza necesarias, no es decir nada si no se añaden unas mínimas explicaciones que permitan descartar la utilización de esa fórmula al antojo de quien debe hacer la designación. Explicaciones que deben ofrecer una concreción, aún elemental, de cuál es la idoneidad de la que se habla y de por qué ninguno de los solicitantes la posee ni es merecedor de confianza».

Esta línea jurisprudencial proviene de la doctrina originada con motivo del examen de los denominados nombramientos discrecionales de la Carrera Judicial, y así, la sentencia de 3 de diciembre de 2012 del Tribunal Supremo, Sala Tercera, de lo Contencioso-administrativo, Sección 7. a , de 3 diciembre 2012, Rec. n. ${ }^{\circ}$ 339/2012; remitiéndose a la sentencia del Tribunal Supremo, Sala Tercera, de lo Contencioso-administrativo, Sección 7.a, de 30 septiembre 2009, Rec. n. ${ }^{\circ}$ 28/2006, señala que «es trasladable a estos nombramientos funcionariales por libre designación la doctrina que el Pleno de esta Sala Tercera del Tribunal Supremo ha sentado sobre los nombramientos discrecionales para cargos jurisdiccionales en las Sentencias de 29 de mayo de 2006 (recurso 309/2004) y 27 de noviembre de 2007 (recurso 407/2006), en las que expresamente se declaran superados los anteriores pronunciamientos jurisprudenciales (en las SSTS de 3 de febrero de 1997 y 30 de noviembre de 1999) que habían apuntado la innecesaridad e inexigibilidad de motivación en esa clase de nombramientos».

El fundamento de esa nueva doctrina jurisprudencial considera que la libertad de nombramiento no es absoluta sino que tiene unos límites, y estos son los exigidos por el orden axiológico constitucional, en concreto, los mandatos constitucionales que proscriben la arbitrariedad (art. 9.3 CE), el respeto al derecho fundamental de todos ellos a acceder en condiciones de igualdad a las funciones y cargos públicos (art 23.2 CE); y que el criterio material que ha decidido el nombramiento se ha ajustado a los principios de mérito y capacidad (103.3 CE).

Por ello, según la jurisprudencia citada existe una doble exigencia en la motivación de la resolución adjudicando el puesto de trabajo, en primer lugar, los concretos criterios de interés general elegidos como prioritarios para decidir el nombramiento, y, en segundo lugar, cuáles son las cualidades o condiciones personales y profesionales que han sido consideradas en el funcionario nombrado para apreciar que aquellos criterios concurren en él en mayor medida que en el resto de los solicitantes.

c) La motivación del cese, reciente doctrina judicial. La Sentencia de la sala contencioso-administrativa del Tribunal Supremo, dictada el 2 de julio de 2020 (rec. 2053/2018), confirma la línea abierta por la sentencia de esa misma Sala de 19 de septiembre de 2019 en relación a un supuesto del cese de Jefe de Servicio que ocupaba el puesto de libre designación.

Pues bien, esta sentencia examina y determina los criterios para poder cesar con una motivación conforme a derecho al funcionario que se encuentre desempeñando un puesto por libre designación, así, esta reciente sentencia fija un criterio básico y que es de imposible discusión, en concreto, que el puesto de trabajo es de nombramiento discrecional, y por lo tanto el cese también es discrecional, si bien, eso no supone que la decisión pueda ser arbitraria, de forma que resulta necesario que la misma se encuentre motivada, así señala:

«Conviene tener en cuenta que, a tenor de nuestra propia jurisprudencia, el funcionario que ocupa un puesto de libre designación no se encuentra cubierto por la inamovilidad en el cargo, y que su cese tiene un componente de libre apreciación evidente que, no obstante, no le exime, como hemos repetido, de motivar las razones de la decisión».

Con relación a los requisitos formales del cese, señala:

«Como el acto de nombramiento, también el de cese debe ajustarse a exigencias formales obvias como, por ejemplo, que lo acuerde el órgano competente o la adecuada formación -en su caso- de la voluntad si es un órgano colegiado y a tales exigencias formales cabe añadir la motivación si bien con la debida modulación».

Dicho lo anterior, el Tribunal Supremo, examina los requisitos de los motivos legítimos para el cese:

1. «que las condiciones subjetivas u objetivas, tenidas en cuenta para la designación, pueden haber desaparecido o cambiado, teniendo en cuenta el interés general que se satisface desde el desempeño del puesto».

2. No es suficiente invocar únicamente que «la motivación de esta resolución se referirá a la competencia para adoptarla».

3. Deben informarse al funcionario cesado «por qué las razones de oportunidad, basadas en la confianza e idoneidad apreciada para el puesto y que llevaron a su elección, ya no concurren o si concurren qué otra circunstancia objetiva determina la pertinencia del cese». 
4. No es suficiente «expresiones opacas, estandarizadas, que puedan encubrir una intención patológica por falsa, caprichosa o ajena a los requerimientos del puesto o a las exigencias de idoneidad profesional que llevaron a la elección».

Esta última exigencia es esencial para poder determinar qué cese se presenta injustificado y el cese que ha de reputarse justificado, ya que se impone en la autoridad que cesa al funcionario, la carga de explicitar un juicio objetivo de inidoneidad, pues no cabe una motivación «ajena a los requerimientos del puesto o a las exigencias de idoneidad profesional que llevaron a la elección».

Esta línea jurisprudencial supone una gran innovación sobre este procedimiento de provisión, ya que, de esta forma se incorporan unos límites a la posible existencia de una actuación administrativa susceptible de ser calificada como de infracción de la arbitrariedad, estableciendo para ello unos parámetros que son susceptibles de examen y control.

\subsubsection{Propuestas para una reconducción de la Libre designación}

Pues bien, expuestas las múltiples razones que justificarían el destierro de la figura de la libre designación como instrumento de provisión de puestos de trabajo en nuestro ordenamiento jurídico, y las graves consecuencias que ha supuesto su utilización para el funcionamiento eficaz y ético de nuestras administraciones públicas, ha llegado el momento de formular algunas propuestas de lege ferenda, que ya expuse en anteriores trabajos ${ }^{40}$ y que debemos reiterar, así:

a) En el caso de que se mantenga el procedimiento de libre designación, estimamos necesario modificar su régimen legal tanto en la «excepcionalidad» de su uso, restringiéndola al máximo, y no ampliando los casos como ha ocurrido con la reforma local de la Ley 27/2013 LRSAL, en su nuevo artículo 92 bis núm. $6^{41}$ y en la legislación de muchas comunidades autónomas, a lo que se debería añadir la necesidad de una motivación específica sobre la concurrencia de un supuesto excepcional.

b) Asimismo, sería deseable que en las propias convocatorias de libre designación se incorporasen méritos reglados y objetivos para autolimitar el margen del acuerdo de nombramiento, incluso, a nuestro juicio, sería recomendable una modificación legal que estableciera una obligación de incorporar a la convocatoria una previsión en este sentido.

c) La modificación de su régimen jurídico exigiendo la obligada motivación del nombramiento con un contenido mínimo en el sentido manifestado por la doctrina del Tribunal Supremo de las resoluciones de adjudicación.

d) La incorporación legal de la obligatoria intervención de una comisión técnica de evaluación de los méritos aportados por los concursantes, sobre cuyo informe deberá motivar su decisión final el órgano político.

e) Resultaría adecuado, a pesar de que una de las esencias de esta figura sea el libre cese discrecional, la exigencia de una motivación técnica de las razones del cese vinculada al desempeño de las tareas asignadas a los puestos de trabajo, y ello, en evitación de que estemos ante situaciones fundadas en la simple arbitrariedad, y por lo tanto, en la línea abierta por la última jurisprudencia que hemos citado, se permita un adecuado control jurisdiccional de la decisión.

f) Modificación del régimen legal de adjudicación de nuevos puestos de trabajo en caso de cese, y aumentar las garantías de mantenimiento del nivel retributivo, si lo que realmente se busca es garantizar la independencia y objetividad en el ejercicio de sus funciones de unos funcionarios auténticamente profesionales.

\subsubsection{El Concurso Específico: en muchas ocasiones una libre designación encubierta}

Ahora bien, la pregunta es si este procedimiento por sí mismo, a diferencia del procedimiento de libre designación, resulta pernicioso y debe ser suprimido, y la respuesta, a mi juicio, como ya he indicado en

40 FONDEVILA ANTOLÍN, J. (2015b), op. cit. y (2018c), op. cit., págs. 123 y ss.

41 FONDEVILAANTOLÍN, J, (2014), "La Reforma y el Empleo Local. Una caja de sorpresas, pero pocas buenas", en CARRILLO DONAIRE y NAVARRO RODRÍGUEZ (coords.), La Reforma del Régimen Jurídico de la Administración Local, Wolters Kluwer. La Ley. El Consultor de los Ayuntamientos, Madrid, págs. 504 y ss. 
trabajos anteriores ya indicados, es que no, y ello, por cuánto estimo que el mismo puede constituir un instrumento técnico adecuado para la provisión de puestos de trabajo de carácter singularizado, especialmente las jefaturas de servicio y sección. Si bien considero que la actual regulación resulta demasiado abierta y necesita una revisión, incluso de carácter básico en el TREBEP, de manera que no se limitara su regulación, como ocurre actualmente, a la simple declaración general de la obligación de que el proceso de valoración gire sobre «los méritos y capacidades y, en su caso, aptitudes de los candidatos» (art. 79.1 TREBEP), renunciando, a diferencia de la regulación anterior en la LMRFP, a fijar un listado de los méritos y capacidades a valorar, pues no hay duda de que uno de los problemas más graves a los que nos hemos referido anteriormente, es el proceso de establecimiento de méritos que suponen una cuasi preselección del candidato preferido por la administración, ya que, el establecer una regulación absolutamente abierta y sin ningún tipo de garantías, está permitiendo que las administraciones procedan a incorporar una «imaginativa» variedad y en muchos casos pintorescos méritos ad personam, lo que supone una actuación calificable de arbitrariedad y despotismo. La ausencia de regulación básica expresa abre caminos para que puedan aprobarse leyes autonómicas de desarrollo que opten por el establecimiento de méritos que respondan a criterios que nada tengan que ver con los principios exigibles a la administración pública, es decir, la objetividad y profesionalidad de sus funcionarios para garantizar un adecuado desarrollo de las funciones administrativas con eficacia y sometidas al derecho. A lo anterior debemos añadir que tampoco existe reserva de ley alguna, con lo cual nada impide que estas cuestiones reciban un tratamiento únicamente por vía reglamentaria en el mejor de los casos, cuándo no por las simples órdenes de convocatoria de cada concurso.

Como ya señale en otros trabajos entiendo que resulta interesante y destacable la novedad incorporada al TREBEP, en concreto, la mención expresa a la obligación de que el proceso de valoración se desarrolle sobre «... y, en su caso, aptitudes de los candidatos»; pues este concepto no se encontraba recogido por la anterior legislación, en concreto el artículo 20 de la LMRFP, lo que origino que por la doctrina ${ }^{42}$ se criticara el encaje de las memorias y entrevistas en los concursos específicos, ya que estas figuras estaban más cercanas al concepto de aptitud que con las exigencias legales del principio de mérito, pues la redacción de la LMRFP parecía impedir extender el uso de estas técnicas de valoración más allá de la simple comprobación de los méritos del candidato. Ahora bien, la incorporación de este concepto no es nuevo en nuestro ordenamiento, de todas formas un examen más detallado legal y jurisprudencialmente de esta figura y su delimitación y conexiones con los principios de mérito y capacidad, se puede encontrar en otro trabajo mío ${ }^{43}$.

Por lo tanto, reiteramos las conclusiones ya formuladas a este respecto en otro trabajo ${ }^{44}$, en concreto:

a) Resultaría necesario una nueva regulación básica del TREBEP que precisase los méritos concretos objeto de valoración (listado) y en segundo lugar, vía principio de la «aptitud» o bien, como desarrollo del principio de «profesionalidad», incorporar las nuevas técnicas profesionales de selección para la provisión de puestos de trabajo (pruebas prácticas mediante simulaciones referidas a las funciones generales por áreas funcionales y no al concreto puesto de trabajo; elaboración de un Proyecto sobre tareas del área funcional de los puestos de trabajo), con relación a estas nuevas técnicas debo llamar la atención sobre la experiencia que al respecto se está desarrollando actualmente en la Comunidad Autónoma del País Vasco ${ }^{45}$, con buenos resultados.

b) Por otro lado, rechazamos la utilización de figuras tan subjetivas y susceptibles de manipulación como las entrevistas y memorias que en muchos de los concursos específicos suponen la concesión de la puntuación final necesaria para otorgar el puesto al candidato predeterminado, pues en caso contrario, seguiremos ante ese proceso imparable de introducción de la discrecionalidad en su sentido más amplio en el concurso. De ahí, que como he señalado anteriormente estimo necesario

42 FERREIRA FERnÁNDEZ, A. X. (2002), La Provisión de Puestos de Trabajo en la Administración General del Estado, INAPMAP, Madrid, págs. 176 y 177 y, asimismo, PALOMAR OLMEDA, A. (2003), El Derecho de la Función Pública, Dykinson, Madrid, pág. 562.

43 FONDEVILAANTOLÍN, J. (2007), op. cit., págs. 595 y ss.

44 FONDEVILA ANTOLíN, J. (2015b), op. cit. y (2018c), págs. 123 y ss.

45 A mero título de ejemplo podemos citar la Orden de 24 de mayo de 2016, del Consejero de Administración Pública y Justicia, por la que se aprueban la convocatoria y las bases específicas del concurso para la provisión de puestos de trabajo de niveles de complemento específico I-A, I-B, II-A, II-B, II-C y III-A que pertenecen al área de conocimiento "Área jurídica» reservados a personal funcionario de carrera de la Administración General de la Comunidad Autónoma del País Vasco y sus Organismos Autónomos. 
un cambio al respecto y su sustitución por nuevos instrumentos como lo señalados en el apartado anterior. En el caso del mantenimiento de la entrevista, considero imprescindible la incorporación, de la misma forma que hemos indicado para los procesos selectivos, de la videograbación de la misma, de manera que se garantice al concursante la posibilidad de control e impugnación de las consideraciones valorativas realizadas por la comisión a la misma.

c) Lógicamente, debemos reiterar lo manifestado con relación a la necesidad de que las comisiones de valoración incorporen todas las exigencias sobre composición, funcionamiento, criterios de valoración y su motivación, en los mismos términos que resultan de aplicación en el ámbito de la selección.

d) Finalmente, indicar que también estimamos esencial la función del orden jurisdiccional contencioso administrativo, que, a nuestro juicio, a la vista de la jurisprudencia debería incrementar, del mismo modo que está ocurriendo con relación al principio de la discrecionalidad técnica y transparencia, el control sobre el uso de esta clase de procedimientos examinando con mayor detalle los listados de méritos objeto de valoración, y que como ya hemos indicado, en muchos casos están construidos ad hoc, ya que, la figura de la «potestad de autoorganización» de las administraciones públicas, no puede ser un «bálsamo de fierabrás» que ampare toda clase de decisiones, es decir, es necesario profundizar en el contraste entre lo objetivo y las adaptaciones ad personam, si bien, es cierto, que en muchas ocasiones solo un conocimiento profundo de la organización y funcionamiento de una determinada administración permite apreciar esa clase de arbitrariedades, y los medios asignados a la Administración de Justicia precisamente no colaboran a este respecto. Por ello, como hemos señalado resulta absolutamente necesario una nueva regulación más detallada y garantista de los procedimientos de provisión de puestos de trabajo por concurso, tanto los generales como, en especial, los específicos.

\subsubsection{Una consideración final: la necesidad de un marco normativo específico para las entidades locales}

Por último, como ya hemos expuesto en otro trabajo ${ }^{46}$, estimo que una clara disfunción en el diseño del empleo público en el ámbito de las entidades locales de mediano y pequeño tamaño se encuentra en el desarrollo de la carrera administrativa. Efectivamente, con plantillas tan reducidas como las de esos municipios la carrera vertical carece de sentido, y al contrario suele suponer que la misma se utilice en claro fraude legis, pues al final se termina creando puestos de trabajo artificiales que no responden a la realidad de las funciones a desempeñar y cuya única finalidad es incrementar las retribuciones del personal aumentando su complemento de destino y específico, pero sin que exista en la realidad una correspondencia con las auténticas funciones desempeñadas.

Por ello, resulta imprescindible la regulación de una carrera administrativa horizontal específica para esta clase de entidades locales, a mi juicio, esta es la única forma de evitar la inflación de puestos de trabajo singularizados que se aprecia en muchas de estas entidades locales que carecen de fundamento, razón organizativa y unos procesos de provisión marcadamente condicionados, y por lo tanto, resultaría lo más adecuado establecer para estas la utilización única y exclusiva de la carrera horizontal, y solo bajo determinadas condiciones económicas y organizativas sería posible la utilización de la carrera vertical.

Y finalmente, estimamos también recomendable que se regulara legalmente un régimen común para las entidades locales de dimensiones similares, estableciendo un límite máximo de puestos de libre designación en cada entidad local en función del presupuesto, población, volumen y composición de la plantilla, u otro criterio objetivo, como se ha regulado para el personal eventual de confianza política por la LRSAL, de manera que se evitasen situaciones de un uso excesivo y no justificado objetivamente de este instrumento y cuyo origen sería el clientelismo.

\section{REFERENCIAS BIBLIOGRÁFICAS}

CONSEJO ECONÓMICO Y SOCIAL (CES) (2005): Informe 3/2004, de 22 de diciembre, sobre La Temporalidad en el Empleo Público. Sesión ordinaria del Pleno de 22 de diciembre de 2004. 1. a ed. Colección Informes. Madrid: Consejo Económico y Social. http://www.ces.es/documents/INF/2004/03.

CHAVES GARCÍA, J. R. (2017): Vademécum de oposiciones y concursos, págs. 187 y ss. Salamanca: Amarante.

46 FONDEVILAANTOLÍN, J. (2018c), op. cit., pág. 280. 
DA. Nueva Época - N. 7, enero-diciembre 2020 - ISSN: 1989-8983 - DOI: https://doi.org/10.24965/da.i7.10898 - [Págs. 63-87]

Los Claroscuros del EBEP en los procedimientos de concurrencia competitiva: reflexiones empíricas y propuestas innovadoras

Jorge Fondevila Antolín

CHAVES GARCÍA, J. R. (2009): La sombra del cese fulminante sobre el letrado público de libre designación, en el blog: https://delajusticia.com/2009/09/19/la-sombra-del-cese-fulminante-sobre-el-letrado-publico-de-libre-designacion/.

DEFENSOR DEL PUEBLO (2003): Funcionarios Interinos y Personal Eventual: la provisionalidad y temporalidad en el empleo público. Informes, Estudios y Documentos. Madrid: Defensor del Pueblo. https://www.defensordelpueblo. es/wp-content/uploads/2015/05/2003-01-Funcionarios-interinos-y-personal-eventual-la-provisionalidad-ytemporalidad-en-el-empleo-p\%C3\%BAblico.pdf.

FERREIRA FERNÁNDEZ, A. X. (2002): La Provisión de Puestos de Trabajo en la Administración General del Estado, págs. 176 y 177. Madrid: INAP-MAP.

FONDEVILA ANTOLÍN, J. (2020): "La Administración electrónica y la celebración de ejercicios en los procesos selectivos: una necesaria innovación, pero con algunas dificultades legales para su implementación”, El Consultor de los Ayuntamientos, núm. 9, sección Rincón local, pág. 114.

FONDEVILA ANTOLÍN, J. (2019a): "La patente de corso otorgada por la jurisdicción social para la arbitraria contratación del personal de las sociedades públicas", Actualidad Administrativa, núms. 7-8, julio-agosto.

FONDEVILA ANTOLÍN, J. (2019b): "El cuestionable amparo de la Jurisdicción Social y la arbitrariedad en el acceso al empleo en las sociedades públicas", Revista Vasca de Gestión de personas y organizaciones públicas, núm. 17, págs. 104-129. https://www.ivap.euskadi.eus/contenidos/informacion/17_revgp/es_def/Fondevila_104_129.pdf.

FONDEVILA ANTOLÍN, J. (2018a): "Repensar el diseño de los procesos selectivos en el empleo público: respuestas ágiles frente a las necesidades inmediatas y fortalecimiento de la especialización de los órganos de selección", Revista Vasca de Gestión de Personas y Organizaciones Públicas, núm. especial 2, págs. 98-111. https://www. ivap.euskadi.eus/z16-a3rvop/es/contenidos/informacion/especial_2_revgp/es_def/index.shtml.

FONDEVILA ANTOLÍN, J. (2018b): Manual para la selección de Empleados Públicos, 2. ${ }^{a}$ edición (revisada y actualizada). Madrid: Wolters Kluwer. El Consultor de los Ayuntamientos.

FONDEVILA ANTOLÍN, J. (2018c): Problemas y soluciones al empleo público actual: Una Valoración a los 10 años de la aprobación del EBEP, Granada: CEMCI.

FONDEVILA ANTOLÍN, J. (2015a): "Los procedimientos de provisión de puestos de trabajo: profesionalidad y objetividad versus clientelismo político y corrupción”, Actualidad Administrativa, núm. 7-8. Wolters Kluwer. https://revistas.Ialey.es/content/Documento.aspx?params=H4sIAAAAAAAEAO29B2AcSZYIJi9ty nt_SvVK1-B0oQiAYBMk2JBAEOzBiM3mkuwdaUcjKasqgcpIVmVdZhZAzO2dvPfee--999577733ujudTif33_8_ XG̈ZkAWz2zkrayZ4hgKrIHz9-fB8_lorZ7LOnb3bo2du79 D-7i-8zOumqJaf_WRxkS_bHH8X59dPq-mb61X2XIWNvkvXGRtm9efHU_b49IC_q98्uvPXp3-5NnrN8e_MJ9UU1dsA7O-v4P4ftyrGp28AA $\bar{A} A=W K E$.

FONDEVILA ANTOLÍN, J. (2015b): “El Principio de Transparencia: ¿Dónde está en el empleo público en España?”, Aletheia: Cuadernos Críticos del Derecho, núm. 2, págs. 157-192. Monográfico: Ética de la Función Pública y

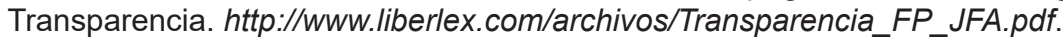

FONDEVILA ANTOLÍN, J. (2014): "La Reforma y el Empleo Local. Una caja de sorpresas, pero pocas buenas", en CARRILLO DONAIRE, J. A.; NAVARRO RODRÍGUEZ, P. (coords.), La Reforma del Régimen Jurídico de la Administración Local, págs. 504 y ss. Madrid: Wolters Kluwer. La Ley. El Consultor de los Ayuntamientos.

FONDEVILA ANTOLÍN, J. (2012): Manual para la selección de Empleados Públicos, 1.ª edición, págs. 184 y ss. Madrid: Wolters Kluwer. El Consultor de los Ayuntamientos.

FONDEVILA ANTOLÍN, J. (2008): La selección y pérdida de la condición de empleado público, pág. 159 y ss. Barcelona: Atelier.

FONDEVILA ANTOLÍN, J. (2007): "Provisión de puestos de trabajo y movilidad", en ORTEGA ÁLVAREZ (dir.), Estatuto Básico del Empleado Público, Madrid: Wolters Kluwer. La Ley. El Consultor de los Ayuntamientos.

FONDEVILA ANTOLÍN, J. (2000): Constitución y Empleo Público, págs. 84 y ss., 201 y ss. Granada: Comares.

GORRITI BONTIGUI, M. (2019): "Gestión planificada de vacantes: retos en Organización y Recursos Humanos", EI Consultor de los Ayuntamientos, número extraordinario 5, Monográfico: La necesaria innovación en el empleo público local: problemas y alternativas, págs. 94-112. Wolters Kluwer.

GORRITI BONTIGUI, M. (2018): "Innovar en selección desde la evidencia empírica y las nuevas competencias", Revista Vasca de Gestión de Personas y Organizaciones Públicas, número especial 2, págs. 66-85. https://www. euskadi.eus/r61-s20001x/es/t59auUdaWar/t59aMostrarFicheroServlet?R01HNoPortal=true\&t59aldRevista=3\&t59 aTipoEjemplar $=R \& t 59 a$ Seccion $=51 \&$ t59aContenido $=8 \& t 59 a$ Correlativo=2\&t59aVersion $=1 \& t 59 a$ NumEjemplar $=14$.

GORRITI BONTIGUI, M.; TOÑA GÜENAGA, F. (2005): "El nuevo modelo de Organización y Recursos Humanos de la Administración General de la Comunidad Autónoma del País Vasco", Presupuesto y Gasto Público, núm. 41, págs. 266 y 267. https://www.ief.es/docs/destacados/publicaciones/revistas/pgp/41.pdf.

INSTITUTO NACIONAL DE ADMINISTRACIÓN PÚBLICA - INAP (2005): Informe de la Comisión para el Estudio y Preparación del Estatuto Básico del Empleado Público, Madrid: INAP, págs. 84 y ss.

LAGUNA DE PAZ, J. C. (2017): "El Control judicial de la discrecionalidad administrativa", Revista Española de Derecho Administrativo, núm. 186, pág. 94 y ss. https://pjenlinea3.poder-judicial.go.cr/biblioteca/uploads/Archivos/ Articulo/El\%20control\%20judicial\%20de\%20la\%20discrecionalidad\%20administrativa.PDF.

MORELL OCAÑA, L. (2001): "Dirección de la Administración Pública por el Gobierno y garantías de imparcialidad administrativa", Revista de Administración Pública, núm. 156, págs. 53 y ss. http://www.cepc.gob.es/publicaciones/ revistas/revistaselectronicas? IDR=1\&IDN=154\&IDA=24394. 
OLMEDA GÓMEZ, J. A.; PARRADO DIEZ, S.; COLINO CÁMARA, C. (2017): Las Administraciones Públicas en España, 2. ${ }^{a}$ ed., Valencia: Tirant lo Blanc.

PALOMAR OLMEDA, A. (2003): "El Derecho de la Función Pública", pág. 562. Madrid: Dykinson.

PONCE SOLÉ, J. (2019): La lucha por el buen gobierno y el derecho a una buena administración mediante el estándar jurídico de diligencia debida, Madrid: Universidad Alcalá de Henares (UAH).

PONCE SOLÉ, J. (2016): "La discrecionalidad no puede ser arbitrariedad y debe ser buena administración", Revista Española de Derecho Administrativo (REDA), núm. 175, enero-marzo. págs. 57-84.

RAMIO MATAS, C. (2019): "Inteligencia artificial y robotización reclaman un nuevo modelo de gestión del empleo público", El Consultor de los Ayuntamientos, número extraordinario 5, Monográfico: La necesaria innovación en el empleo público local: problemas y alternativas. págs. 30-46, Wolters Kluwer.

SANGÜESA CABEZUDO, A. M. ${ }^{a}$ (2016): "Nombramientos de libre designación en la Administración General del Estado. Nombramientos discrecionales. La diferencia entre uno y otro supuesto a la luz de la jurisprudencia", Actualidad Administrativa, núm. 12.

SOSA WAGNER, F. (2007): "Nuevo desalojo del Estado: secretarios e Interventores", Diario el Mundo (30 de abril de 2007), Sección de Opinión.

Temas de hoy, (5 de Julio de 2019), Diario La Ley, núm. 9.450. Wolters Kluwer. 